\title{
Dust Particle Size and Statistical Parameters
}

\author{
Noor Al-Dousari, Modi Ahmed, Ali Al-Dousari, Musaad Al-Daihani, \\ and Murahib Al-Elaj
}

\begin{abstract}
Grain 'size' can be specified and measured in several different ways. All methods of grain size determination have blemishes, and the choice of the most appropriate method is governed by the nature of the sample and the use to which the data are placed. Four main methods are currently used for size analysis of sands: (a) sieving; (b) settling tube analysis; (c) electro-optical methods, including Coulter Counter analysis and laser granulometry; and (d) computerized image analysis. The classification of the particle size distribution of Kuwait dust was mapped according to the parameters proposed by Folk And Ward (1957) which were widely used for quantitative comparisons between natural grain size distribution and the lognormal that shows better sorted sediments have lower values of $\sigma 1$. Maps of the distribution of dust in Kuwait were obtained that included: fine sand (F.S.), Coarse sand (C.S), Medium Sand (M.S), Very Fine Sane (V.F.S), Very Coarse Silt (V.C.Silt), Coarse Silt (C.Silt), Medium Silt (M.Silt), Fine Silt (F.Silt), Very Fine Silt (V.
\end{abstract}

N. Al-Dousari $(\bowtie) \cdot$ M. Ahmed · A. Al-Dousari

Crisis Descision Supports Program (CDS), Environment \& Life Sciences Research Center (ELSRC), Kuwait Institute for Scientific Research (KISR), P.O. Box. 24885 Safat, 13109, Kuwait

e-mail: ndousari@kisr.edu.kw

M. Ahmed

e-mail: mmahmed@kisr.edu.kw

A. Al-Dousari

e-mail: adousari@kisr.edu.kw

M. Al-Daihani

Construction \& Production Department, Kuwait Oil Company

(KOC), P.O. Box. 9758 Ahmadi, 61008, Kuwait

e-mail: mdaihani@kockw.com

\section{Al-Elaj}

Environment \& Life Sciences Research Center (ELSRC), Kuwait Institute for Scientific Research (KISR), P.O. Box. 24885 Safat, 13109, Kuwait

e-mail: maraheb@protonmail.com
F.Silt), in addition to that, the deposition percentage of Clay, Sand, mud (silt plus clay) and silt were provided.

\section{Introduction}

Dust suspended over long distances consists of mud particles that predominantly originate from regional sources such as the Western Desert of Iraq and the Mesopotamian Floodplain, in addition to local dust deposition that produces relatively coarse saltated dust material greater than $63 \mathrm{~mm}$ grain-size fractions. The former type represents $63 \%$ of the dust, and the latter, 37\%. Generally, the distribution of particle size is trimodal and displays slight variation over time. The sand particles, being heavier than mud, move in the form of saltation, are transported for short distances, and predominantly originate from local sources. The grain-size percentages of dust collected in the open desert and coastal areas, such as Bubiyan, vary. Bubiyan dust is negatively skewed, trimodal with clay dominancy coarse, and with fine silt size fractions. The trimodal of the distribution curves indicates multiple sources.

Liyah dust (i.e. open desert) is negatively skewed and unimodal with the dominance of very coarse sand size fraction. There is a trend of a coarsening of the mean size fraction toward the west. Furthermore, the dust particles collected from the western side of the study area are larger and smoother than those from the eastern side. Bubiyan dust is finer and contains more adhering particles, mainly gypsum $\left(\mathrm{CaSO}_{4} \cdot 2 \mathrm{H}_{2} \mathrm{O}\right)$ and bassanite $\left(\mathrm{CaSO}_{4} \cdot 1 / 2 \mathrm{H}_{2} \mathrm{O}\right)$. The average percentages for clay, very fine silt, very coarse silt, and very fine sand in the dust reveal the dominance of clay along the sides of the dunes corridor (Huwaimiliyah-Wafra), Um Umara, north and east Bubiyan, and Bahrat Hushan.

Dust storms cause serious health hazards. 


\section{Methodology}

Grain movement is influenced by the characteristics of individual grains from the source, such as size, shape, and density, but also by the characteristics of the sediment bulk, which include the grain-size distribution (sorting), orientation, packing arrangement, porosity, and cohesion. During transport, grains are sorted according to size and shape due to inter-particle collisions or contact with the bed.

Grain 'size' can be specified and measured in several different ways. All methods of grain-size determination have issues, and the choice of the most appropriate method is governed by the nature of the sample and the use to which the data are made. Four main methods are currently used for the size analysis of sands: (a) sieving; (b) settling tube analysis; (c) electro-optical methods, including Coulter
Counter analysis and laser granulometry; and (d) computerized image analysis.

However, the most widely used method is dry sieving, in which a sand sample is shaken through a nest of successively finer mesh sieves. Conventionally, the weight of the sand retained on each sieve is converted to a percentage of the total sample. Several studies have shown that particle shape can significantly impact the sieve data (Komar and Cui 1984; Kennedy et al. 1985). All the difficulties may be experienced when samples contain a mixture of quartz and parts of the platy crusts (Carter 1982). The deposit particle sizes range from several meters to less than $1 \mu \mathrm{m}$, (Udden 1914; Wentworth 1922). Table 1 presents a graphical representation and statistical manipulation of grain-size frequency data. Krumbein (1934) proposes that the grade boundaries should be logarithmically transformed into phi $(\varphi)$ values.
Table 1 Size scales of Udden (1914) and Wentworth (1922), with class terminology modifications proposed by Friedman and Sanders (1978)

\begin{tabular}{|c|c|c|c|c|c|}
\hline Size $\mathrm{mm}$ & $\mu \mathrm{m}$ & phi & $\begin{array}{l}\text { Sediment size class terminology } \\
\text { of Wentworth (1922) }\end{array}$ & \multicolumn{2}{|c|}{$\begin{array}{l}\text { Sediment size class terminology } \\
\text { of Friedman and Sanders (1978) }\end{array}$} \\
\hline 2048 & & -11 & \multirow[t]{7}{*}{ Cobbles } & very large boulders & \multirow[t]{7}{*}{ grave } \\
\hline 1024 & & -10 & & very large boulders & \\
\hline 512 & & -9 & & large boulders & \\
\hline 256 & & -8 & & medium boulders & \\
\hline 128 & & -7 & & small boulders & \\
\hline 64 & & -6 & & large cobbles & \\
\hline 32 & & -5 & & small cobbles & \\
\hline 16 & & -4 & \multirow[t]{4}{*}{ Pebbles } & very coarse pebbles & \\
\hline 8 & & -3 & & coarse pebbles & \\
\hline 4 & & -2 & & medium pebbles & \\
\hline 2 & 2000 & -1 & & fine pebbles & \\
\hline 1 & 1000 & 0 & Granules & very fine pebbles & \multirow[t]{6}{*}{ sand } \\
\hline 0.5 & 500 & 1 & Very coarse sand & very coarse sand & \\
\hline 0.25 & 250 & 2 & Coarse sand & coarse sand & \\
\hline 0.125 & 125 & 3 & Medium sand & medium sand & \\
\hline 0.063 & 63 & 4 & Fine sand & fine sand & \\
\hline 0.031 & 31 & 5 & Very fine sand & very fine sand & \\
\hline 0.016 & 16 & 6 & \multirow[t]{4}{*}{ Silt } & very coarse silt & \multirow[t]{4}{*}{ silt } \\
\hline 0.008 & 8 & 7 & & coarse silt & \\
\hline 0.004 & 4 & 8 & & medium silt & \\
\hline \multirow[t]{2}{*}{0.002} & 2 & 9 & & fine silt & \\
\hline & & & Clay & very fine silt clay & clay \\
\hline
\end{tabular}




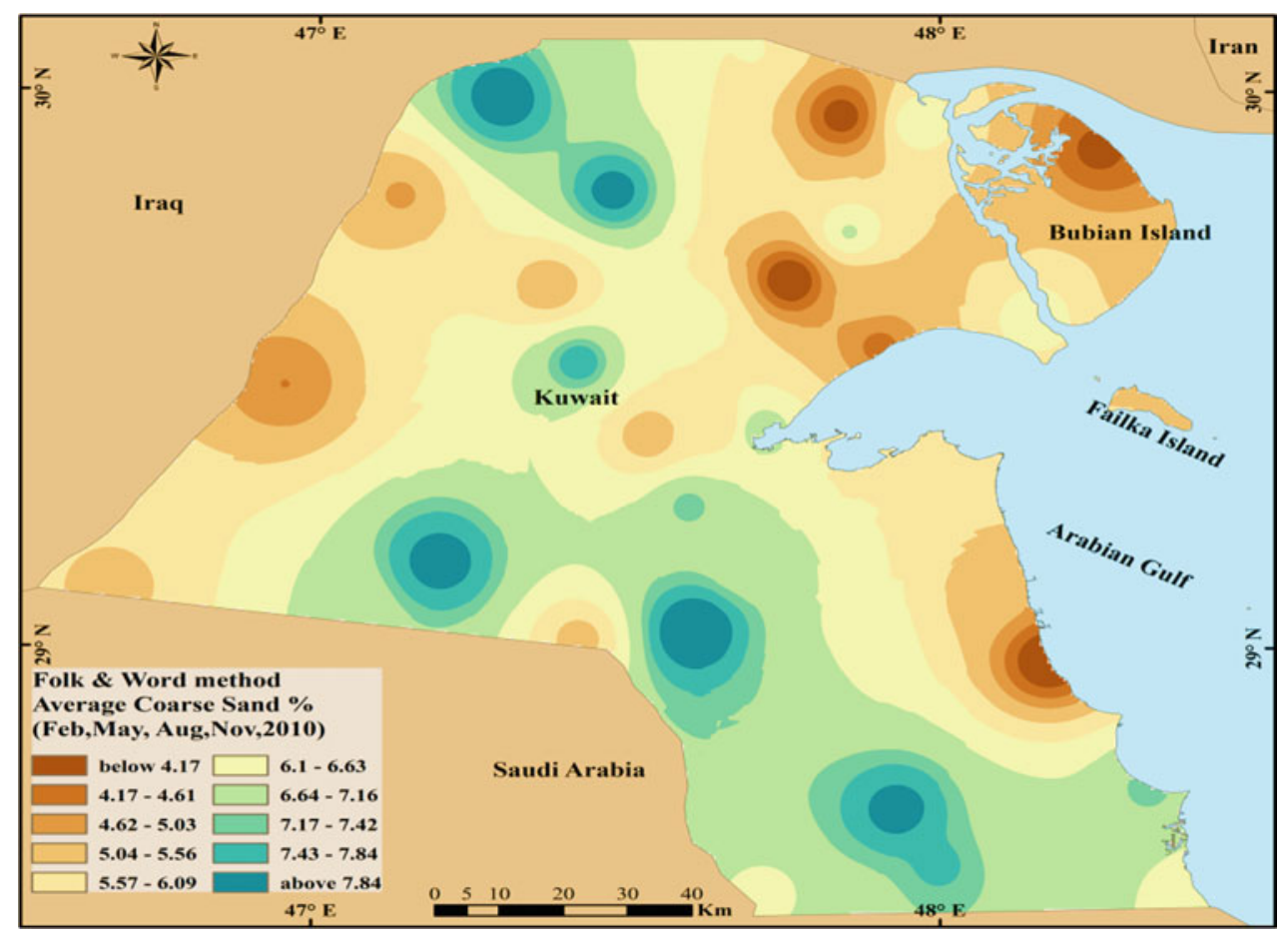

Fig. 3.1 Average percentages of coarse sand in the deposited dust(February, May, August, November 2010)

Coarse sand (C.S.) ranges in size between 0.5 and $1 \mathrm{~mm}$ (1-0 phi). The fallen dust in the northeastern and coastal area of Kuwait had the lowest C.S. percentage. In contrast, Wafra, the southwestern areas of Kuwait, and the Ratqah had the highest C.S. percentage. Although the C.S. percentages are less than $10 \%$ in general, they could indicate size behavior of fallen dust both temporarily and spatially. The highest rates were noted in February.

\begin{tabular}{l|l}
\hline $\begin{array}{l}\text { Areas with high particle size } \\
\text { concentration }\end{array}$ & $\begin{array}{l}\text { Areas with low particle size } \\
\text { concentration }\end{array}$ \\
\hline Ratqah & Bubiyan Island \\
Dibdibah & Shuaiba \\
Um qudayr & Um Rimam \\
Wafra & Ubayriq \\
\hline
\end{tabular}



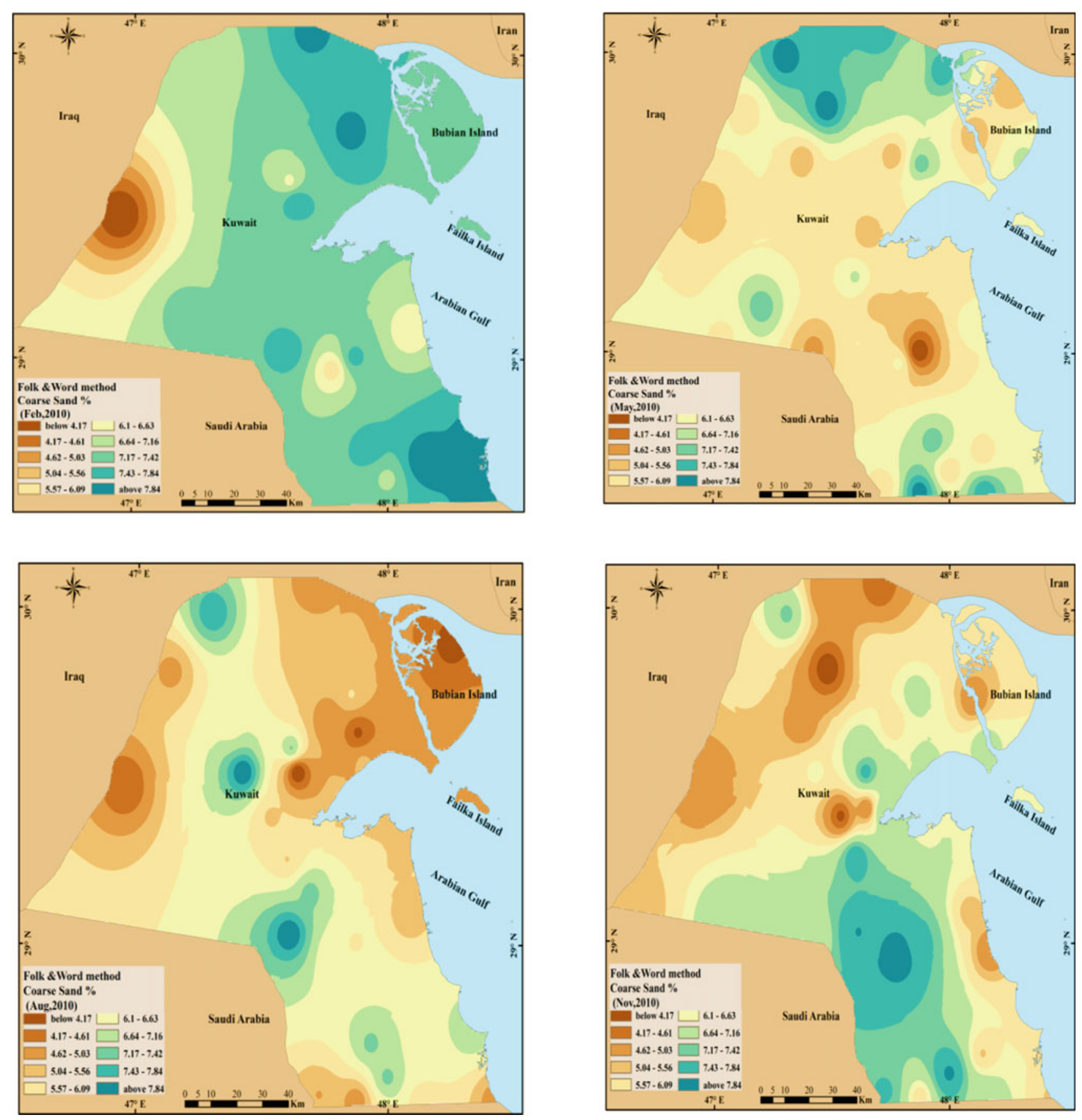

Fig. 3.2 Coarse sand size fractions percentages in Feb, May, Aug, Nov 2010 


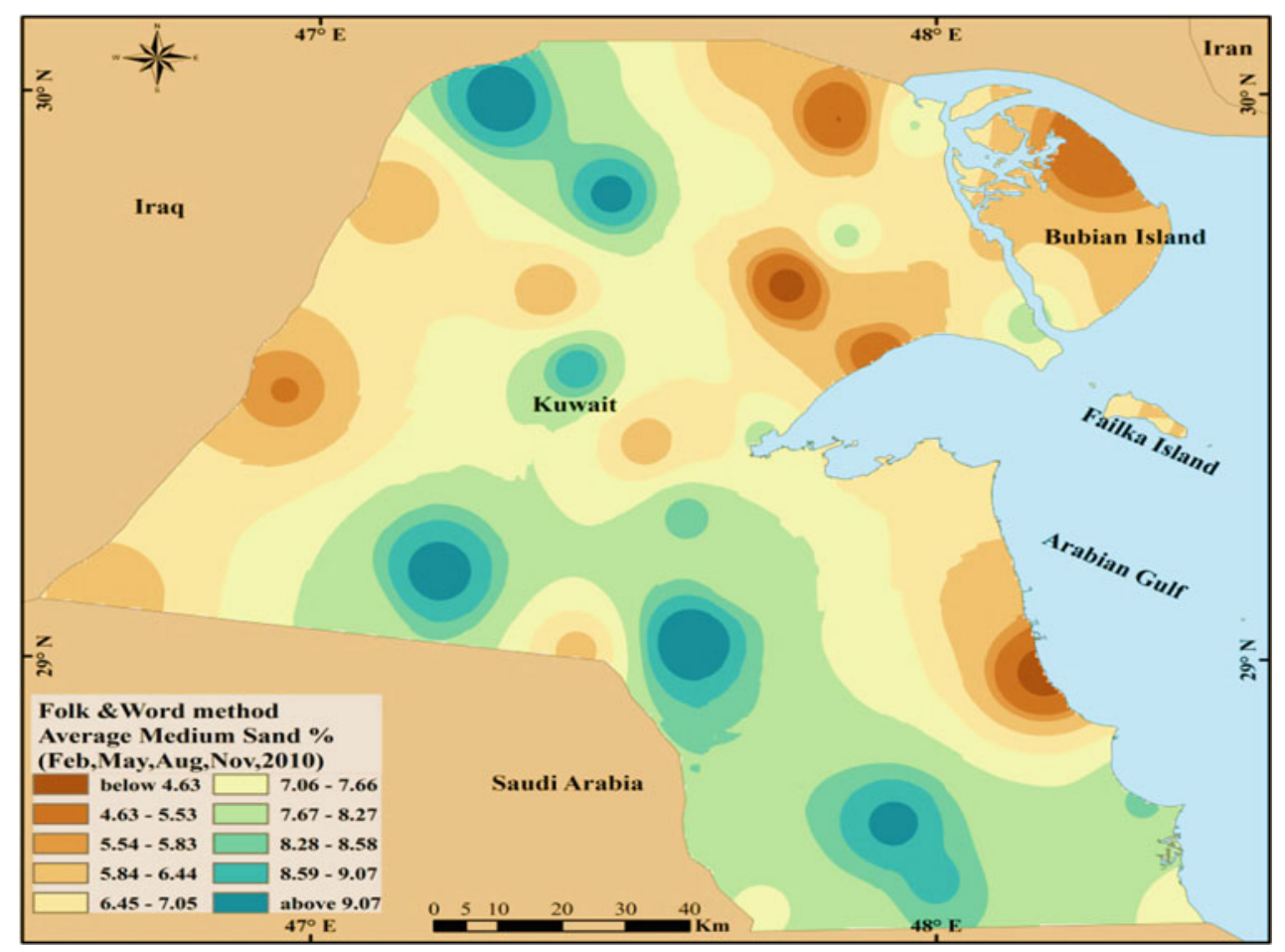

Fig. 3.3 Average percentages of medium sand in the deposited dust (February, May, August, November 2010)

Medium sand (M.S.) ranges in size between 0.25 and $0.5 \mathrm{~mm}(2-1 \mathrm{phi})$. It had a similar distribution to C.S. Furthermore, February's fallen dust had the highest percentages. It has always been noted that the southern areas of Kuwait are characterized by sandy dust more than most other areas in the country, as they experience the highest aeolian accumulation. On the other hand, the northern and northeastern areas of Kuwait have the lowest percentages of M.S. size fraction. In August, the M.S. had a higher percentage within the major wind or dune corridor in Kuwait.

\begin{tabular}{l|l}
\hline $\begin{array}{l}\text { Areas with high particle size } \\
\text { concentration }\end{array}$ & $\begin{array}{l}\text { Areas with low particle size } \\
\text { concentration }\end{array}$ \\
\hline Ratqah & Bubiyan Island \\
Dibdibah & Gudhi \\
Kabd & Shuaiba \\
Wafra Farms & Ubayriq \\
\hline
\end{tabular}



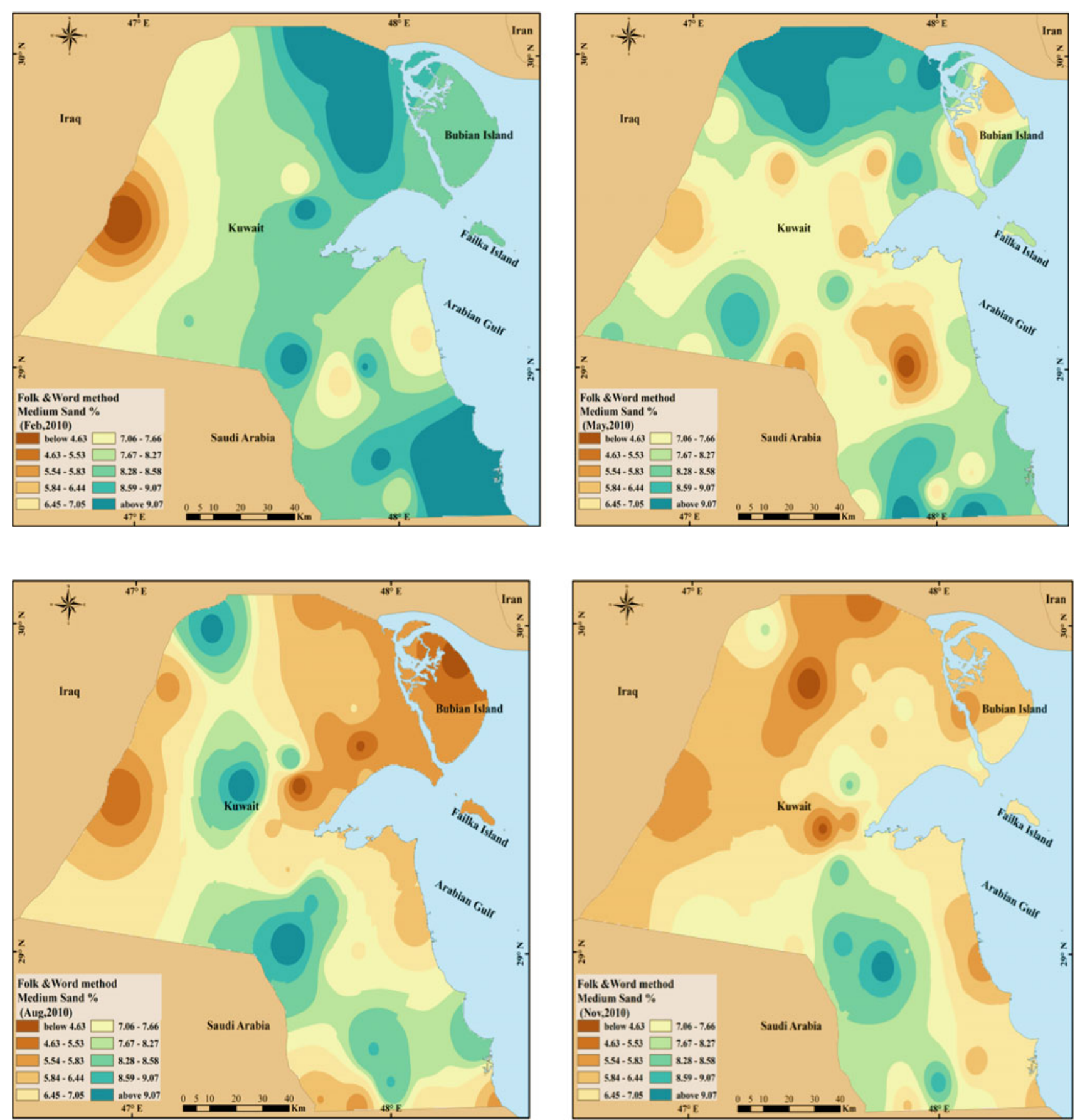

Fig. 3.4 Medium sand size fraction percentages in Feb, May, Aug, Nov 2010 


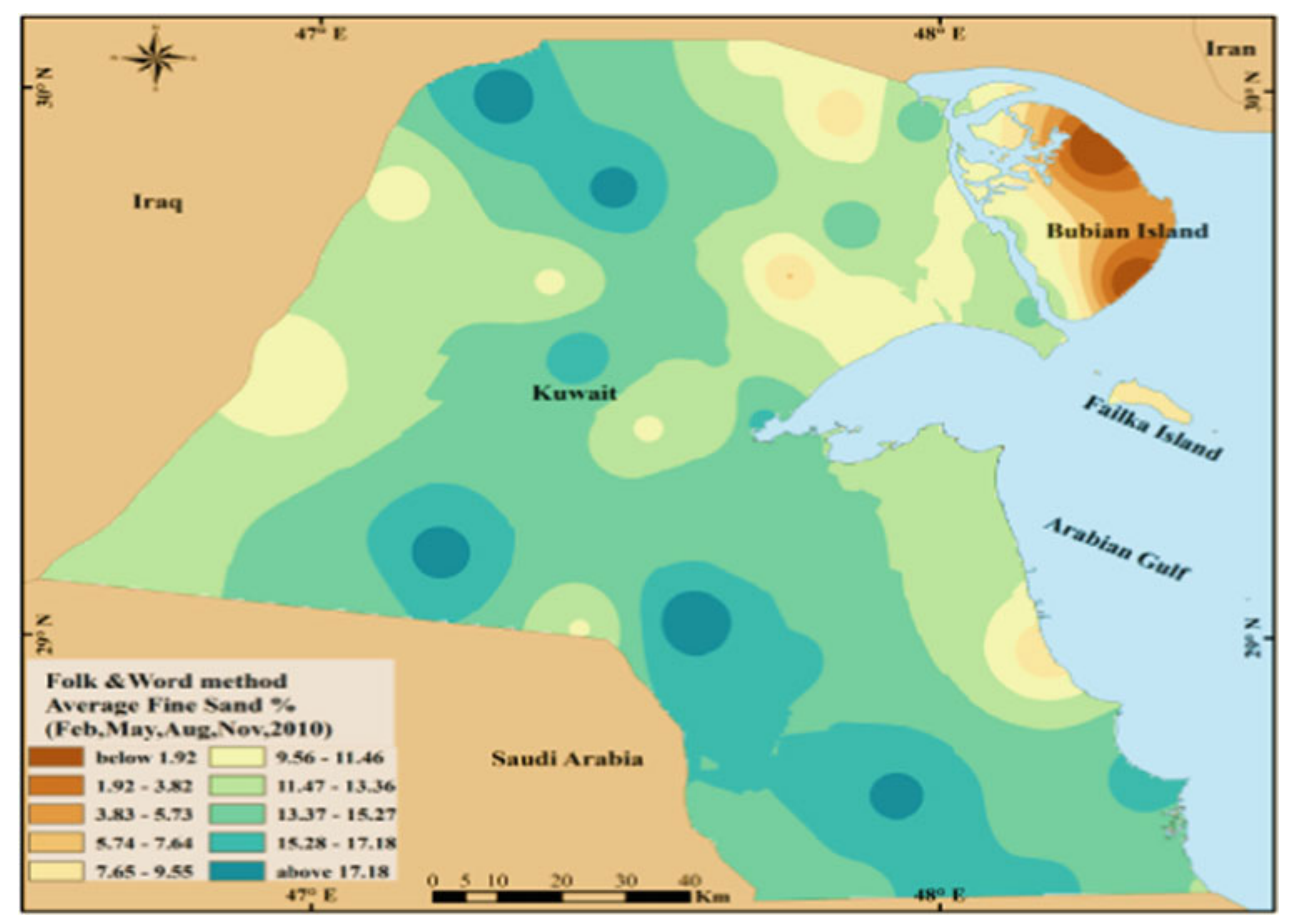

Fig. 3.5 Average percentages of fine sand in the deposited dust (February, May, August, November 2010)

Fine sand (F.S.) ranges in size between 0.125 and $0.25 \mathrm{~mm}$ (3-2 phi). It had a similar trend of distribution to C.S. and M.S., but the percentages are about twice of those. The highest rates were recorded in February. The highest percentages were in a corridor that extends from the Retqah toward the Wafra in Kuwait. On the other hand, the lowest rates of M.S. size fraction were noted on Bubiyan Island and the northeastern areas of Kuwait.

\begin{tabular}{l|l}
\hline $\begin{array}{l}\text { Areas with high particle size } \\
\text { concentration }\end{array}$ & $\begin{array}{l}\text { Areas with low particle size } \\
\text { concentration }\end{array}$ \\
\hline Ratqah & Bubiyan Island \\
Dibdibah & Failaka Island \\
Kabd & Gudhi \\
Wafra Farms & Abdulli \\
\hline
\end{tabular}



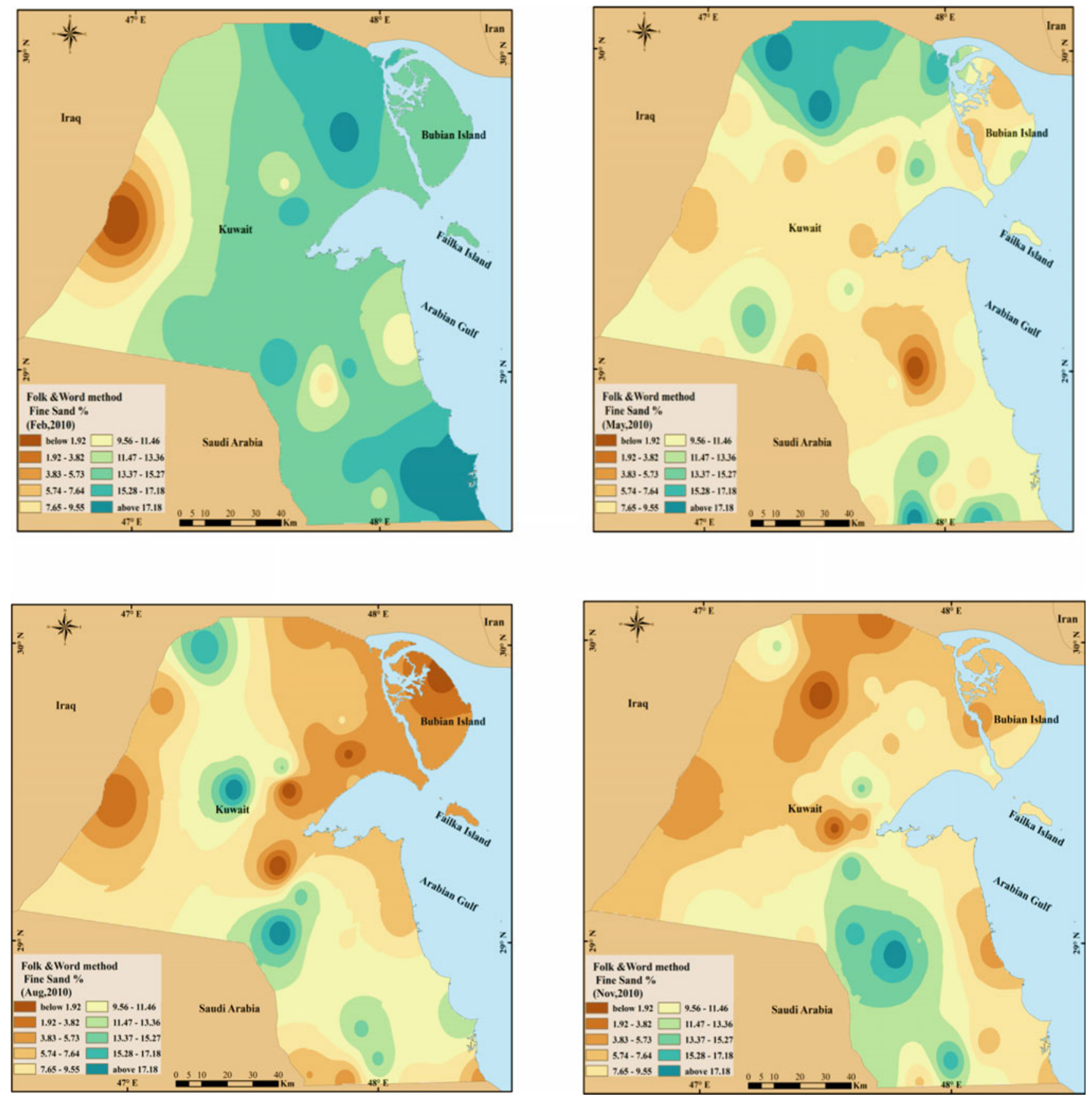

Fig. 3.6 Fine sand size fractions percentages in Feb, May, Aug, Nov 2010 


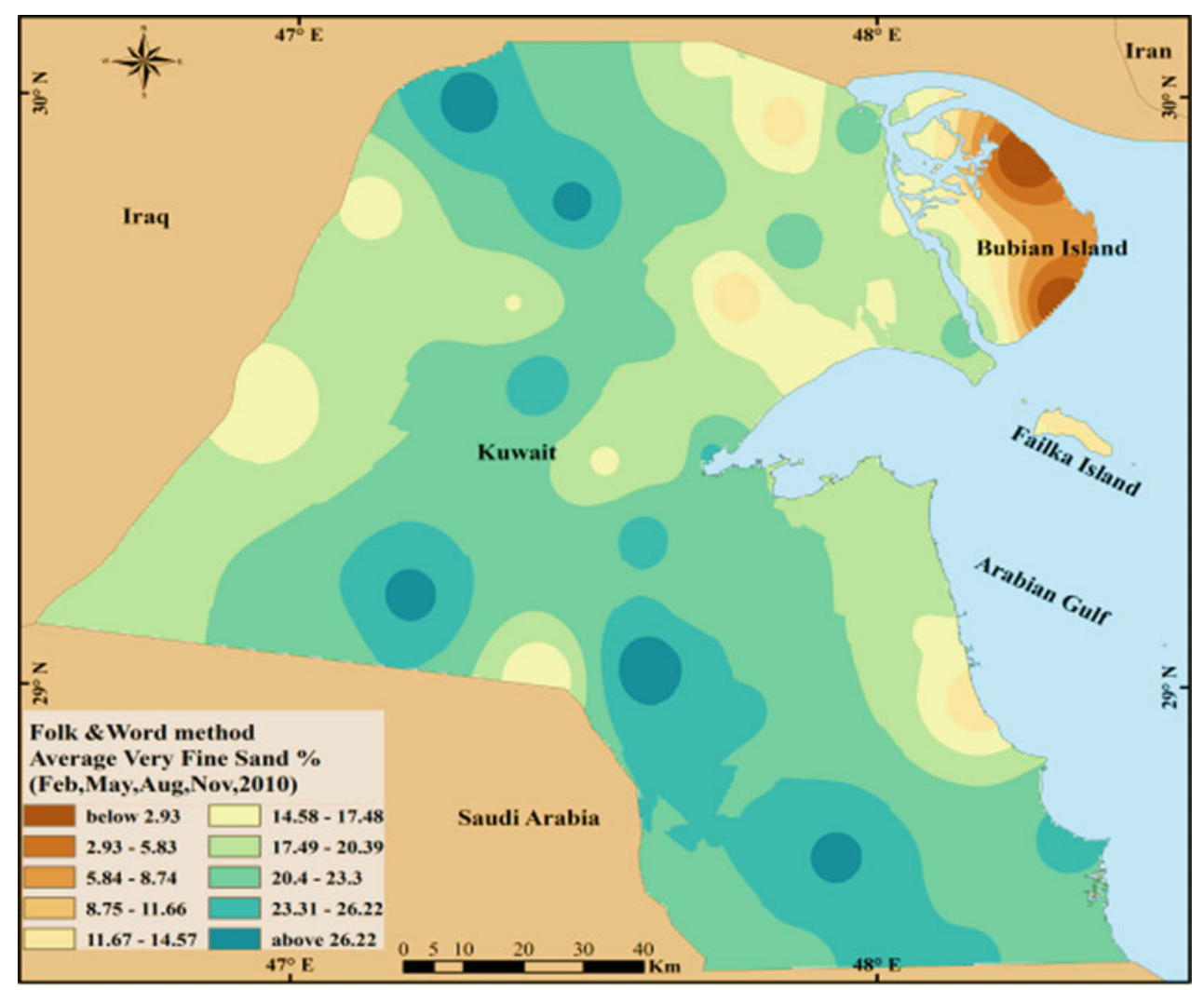

Fig. 3.7 Average percentages of very fine sand in the deposited dust (February, May, August, November 2010)

Very fine sand (V.F.S.) ranges in size between 0.063 and $0.125 \mathrm{~mm}$ (4-3 phi). It had a similar trend of distribution to C.S. and M.S., but the percentages were much more than twice the amount. The highest percentage rates were noted in February. The highest percentages were in a corridor that extends from the Retqah area toward the Wafra area in Kuwait. On the other hand, the lowest percentage rates of V. F.S. were recorded on Bubiyan Island and in the northeastern areas of Kuwait.
Areas with high particle size concentration

\begin{tabular}{l|l}
\hline Ratqah & Bubiyan Island \\
Dibdibah & Failaka Island \\
Kabd & Gudhi \\
Wafra Farms & Abdulli \\
\hline
\end{tabular}

Areas with low particle size concentration

Abdulli 

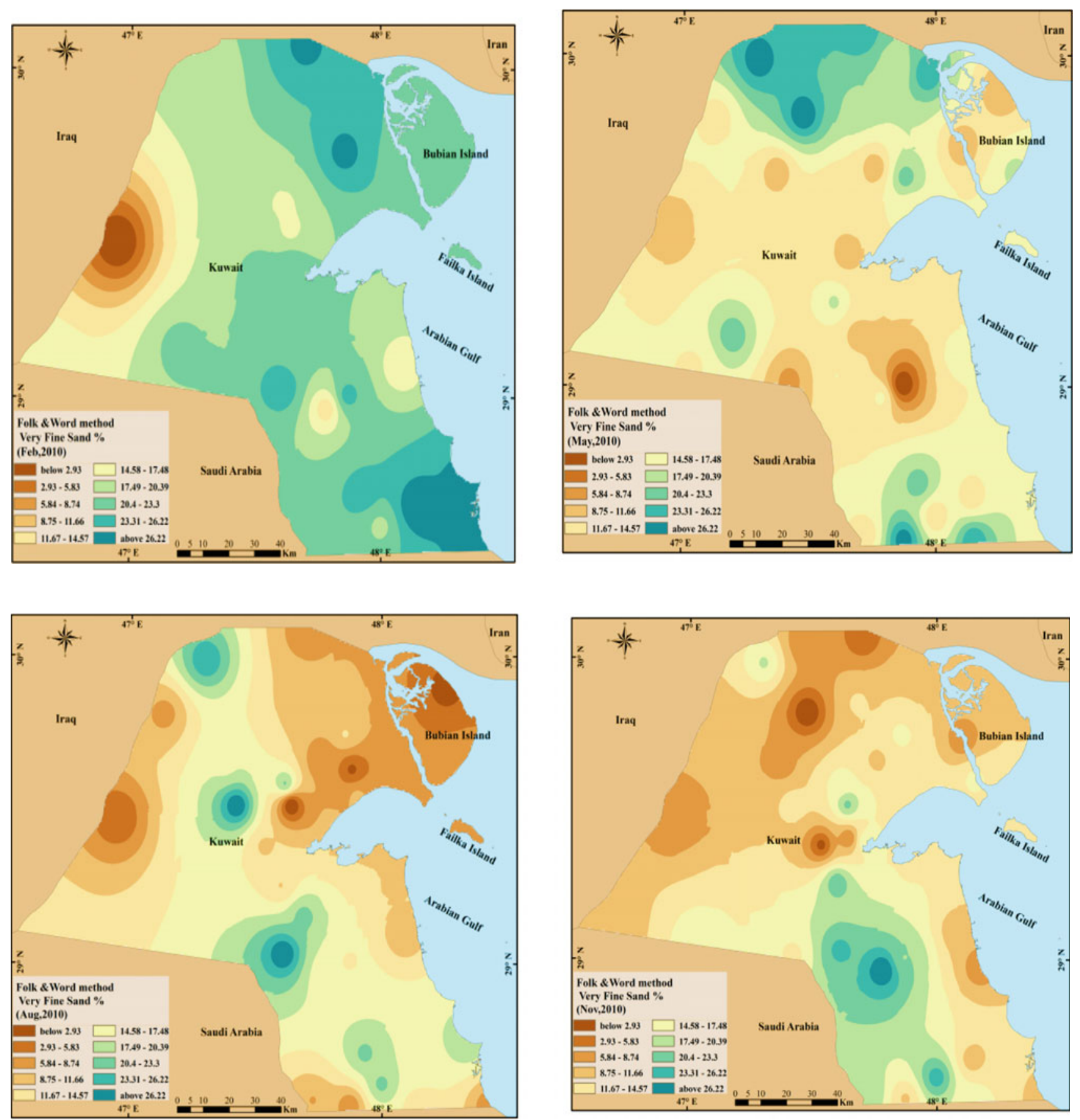

Fig. 3.8 Very fine sand size fractions percentages in Feb, May, Aug, Nov 2010 


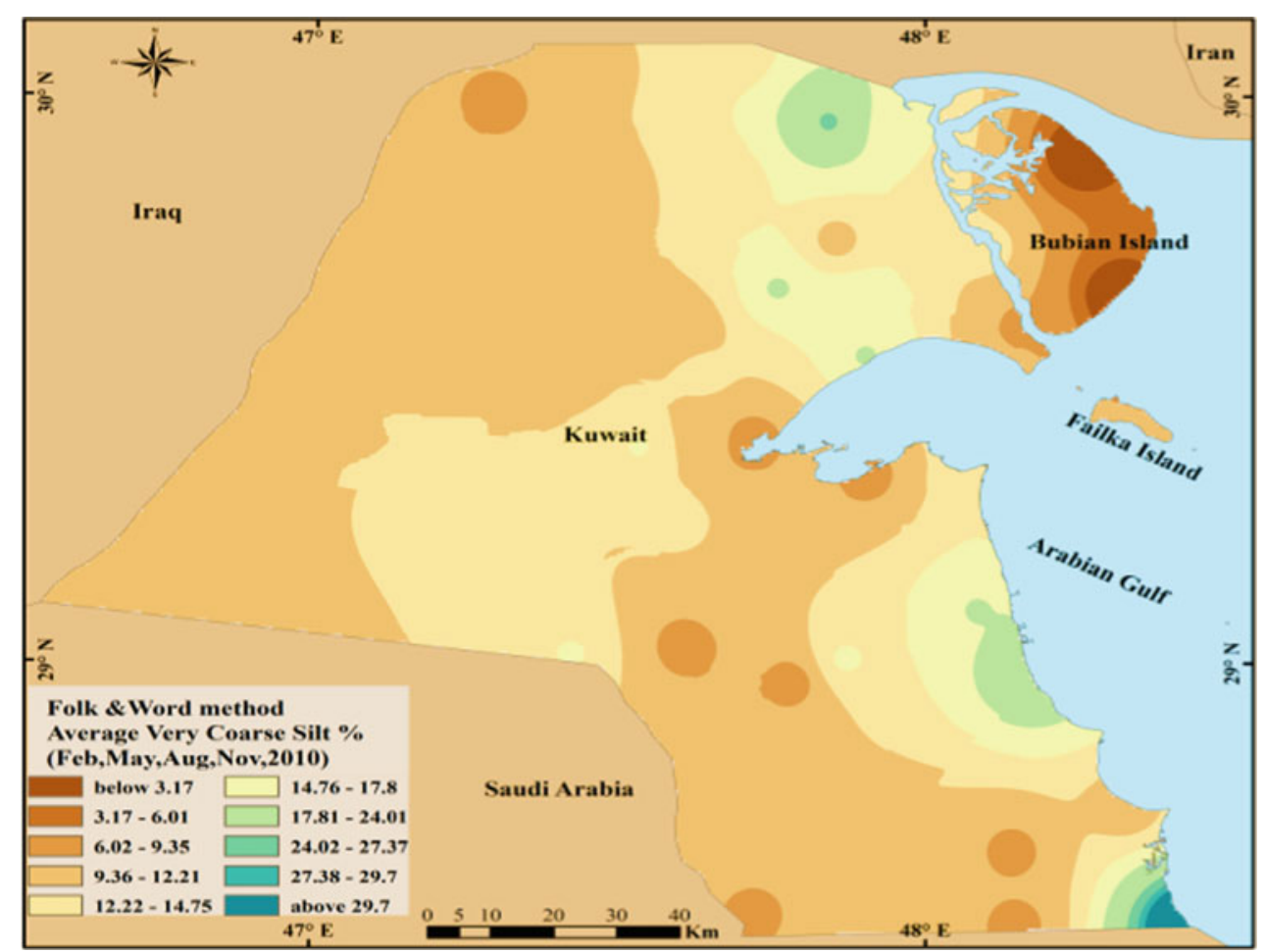

Fig. 3.9 Average percentages of very coarse silt in the deposited dust (February, May, August, November 2010)

Very coarse silt (V.C. Silt) ranges in size between 0.031 and $0.063 \mathrm{~mm}(4-5 \mathrm{phi})$. V.C. Silt was present in higher percentages toward the coastal areas of Kuwait. The lowest percentages were in May. The V.C. Silt and the C. Silt had lower rates within the major wind or dune corridor in Kuwait during August. The lowest percentages were recorded in the eastern part of Bubiyan Island in all months except August.

\begin{tabular}{l|l}
\hline $\begin{array}{l}\text { Areas with high particle size } \\
\text { concentration }\end{array}$ & $\begin{array}{l}\text { Areas with low particle size } \\
\text { concentration }\end{array}$ \\
\hline Khiran & Bubiyan Island \\
Shuaiba & Subiyah \\
Abdulli & Ratqah \\
Gudhi & Mutla \\
\hline
\end{tabular}



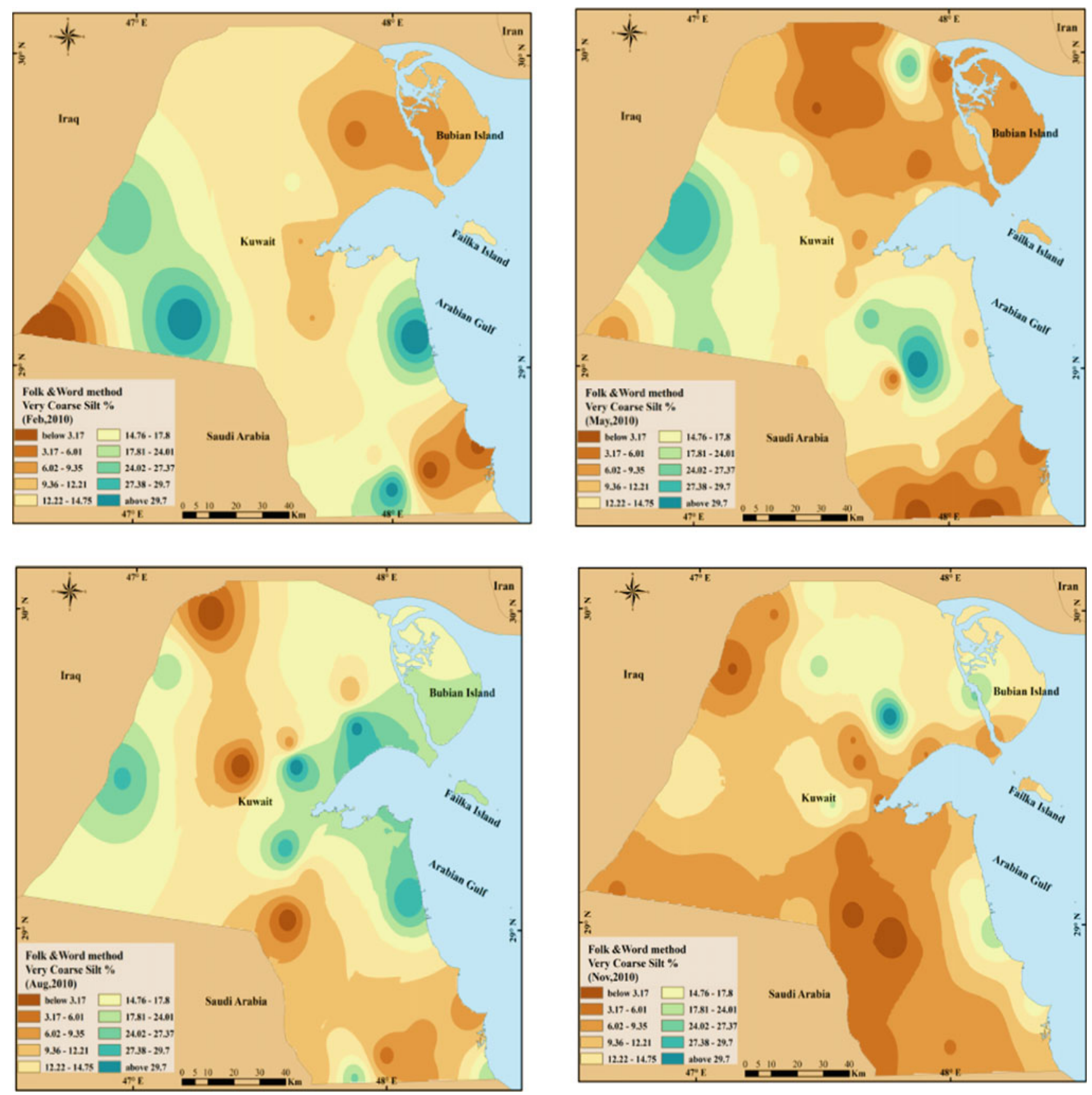

Fig. 3.10 Very coarse silt size fractions percentages in Feb, May, Aug, Nov 2010 


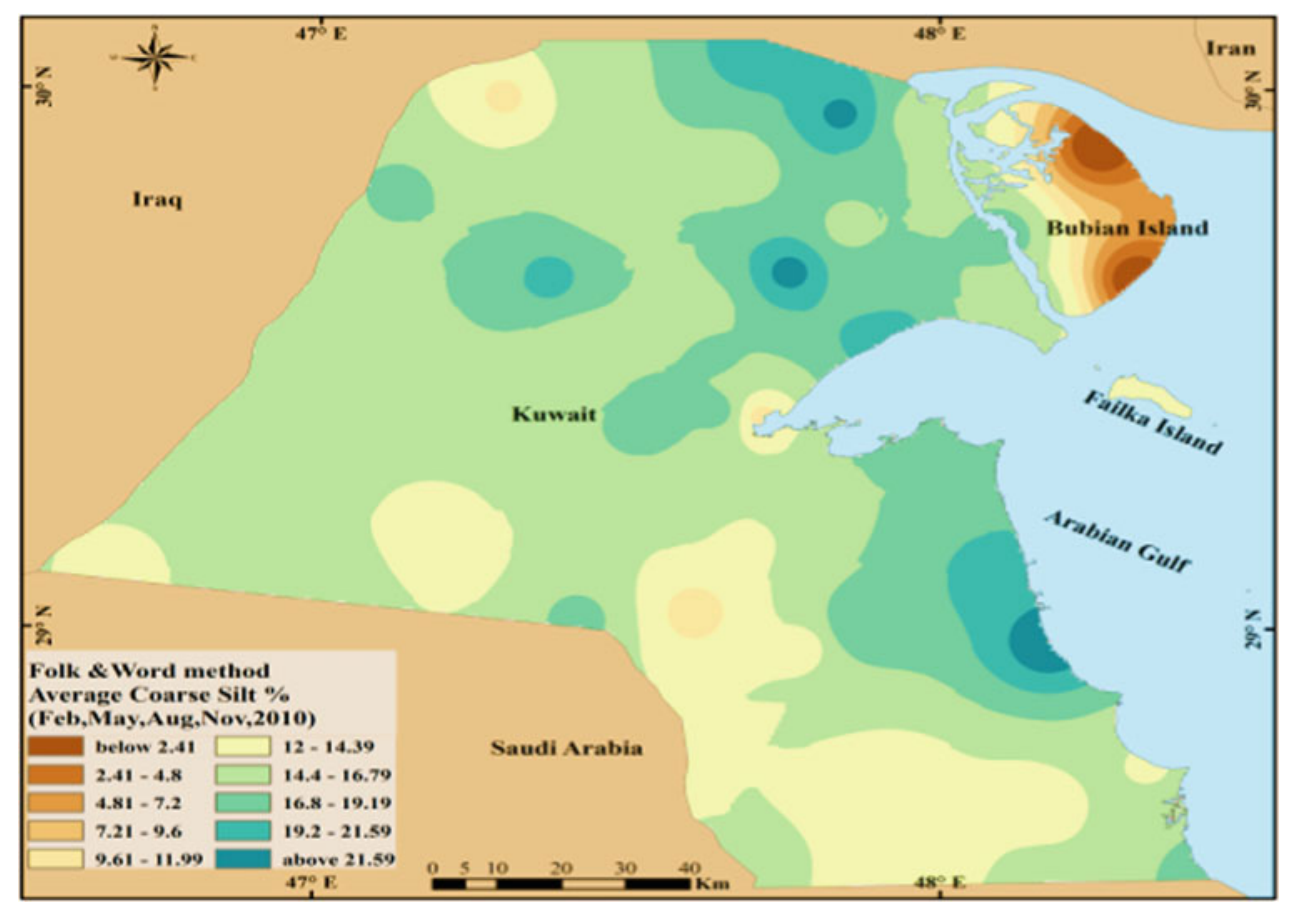

Fig. 3.11 Average percentages of coarse silt in the deposited dust (February, May, August, November 2010)

Coarse silt (C.Silt) ranges in size between $0.031 \mathrm{~mm}$ and $0.016 \mathrm{~mm}$ (6-5 phi). The silt size fractions act as the main component of fallen dust. C.silt was present in higher percentages in the northeastern sector of Kuwait. The lowest percentages were seen during May. The lowest rates were observed in the east of Bubiyan Island.

\begin{tabular}{l|l}
\hline $\begin{array}{l}\text { Areas with high particle size } \\
\text { concentration }\end{array}$ & $\begin{array}{l}\text { Areas with low particle size } \\
\text { concentration }\end{array}$ \\
\hline Abdulli & Bubiyan Island \\
Gudhi & Failaka Island \\
Shuaiba & Dibdibah \\
Huwaymilyah & Wafra Farms \\
\hline
\end{tabular}



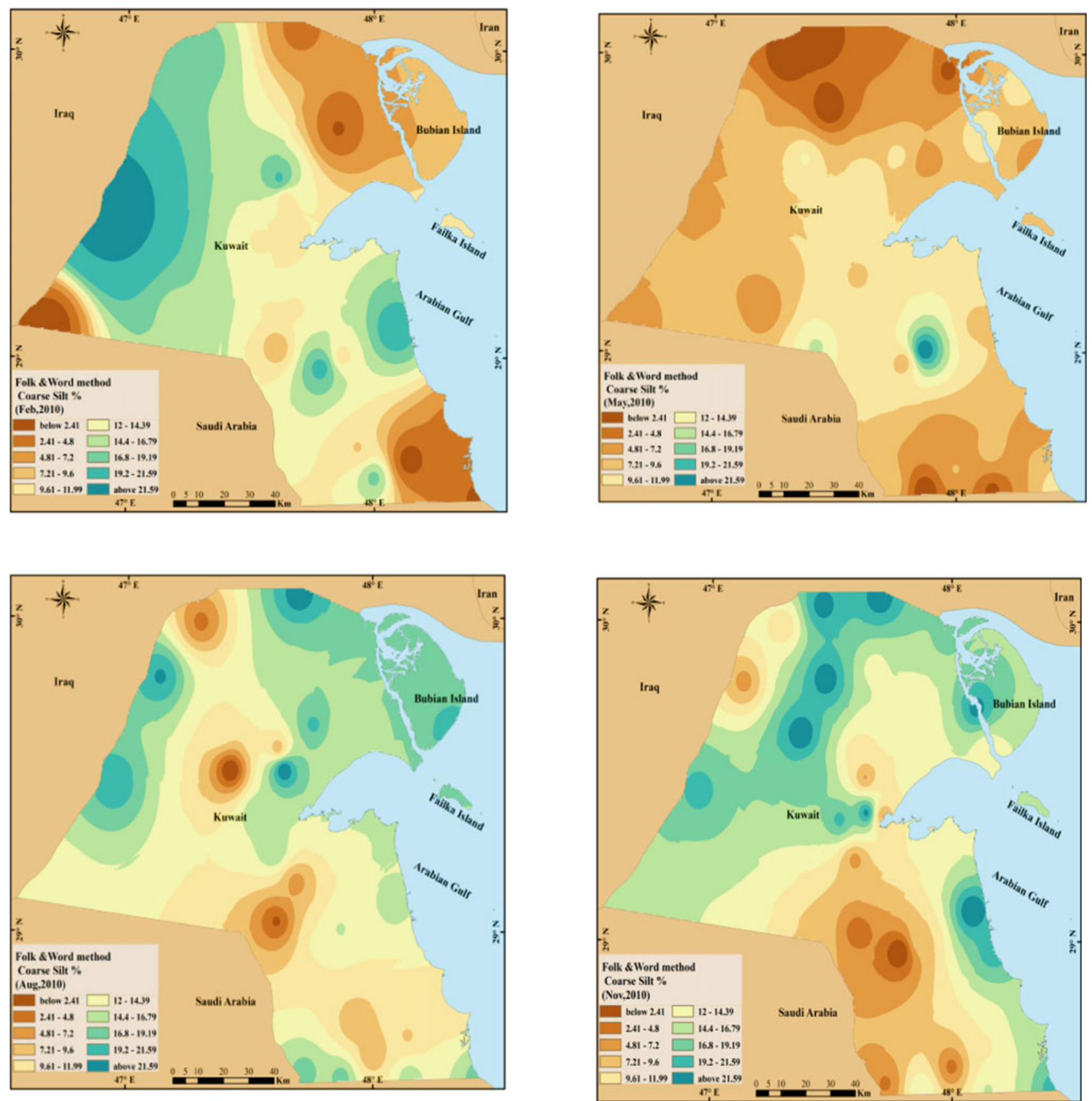

Fig. 3.12 Coarse silt size fractions percentages in Feb, May, Aug, Nov 2010 


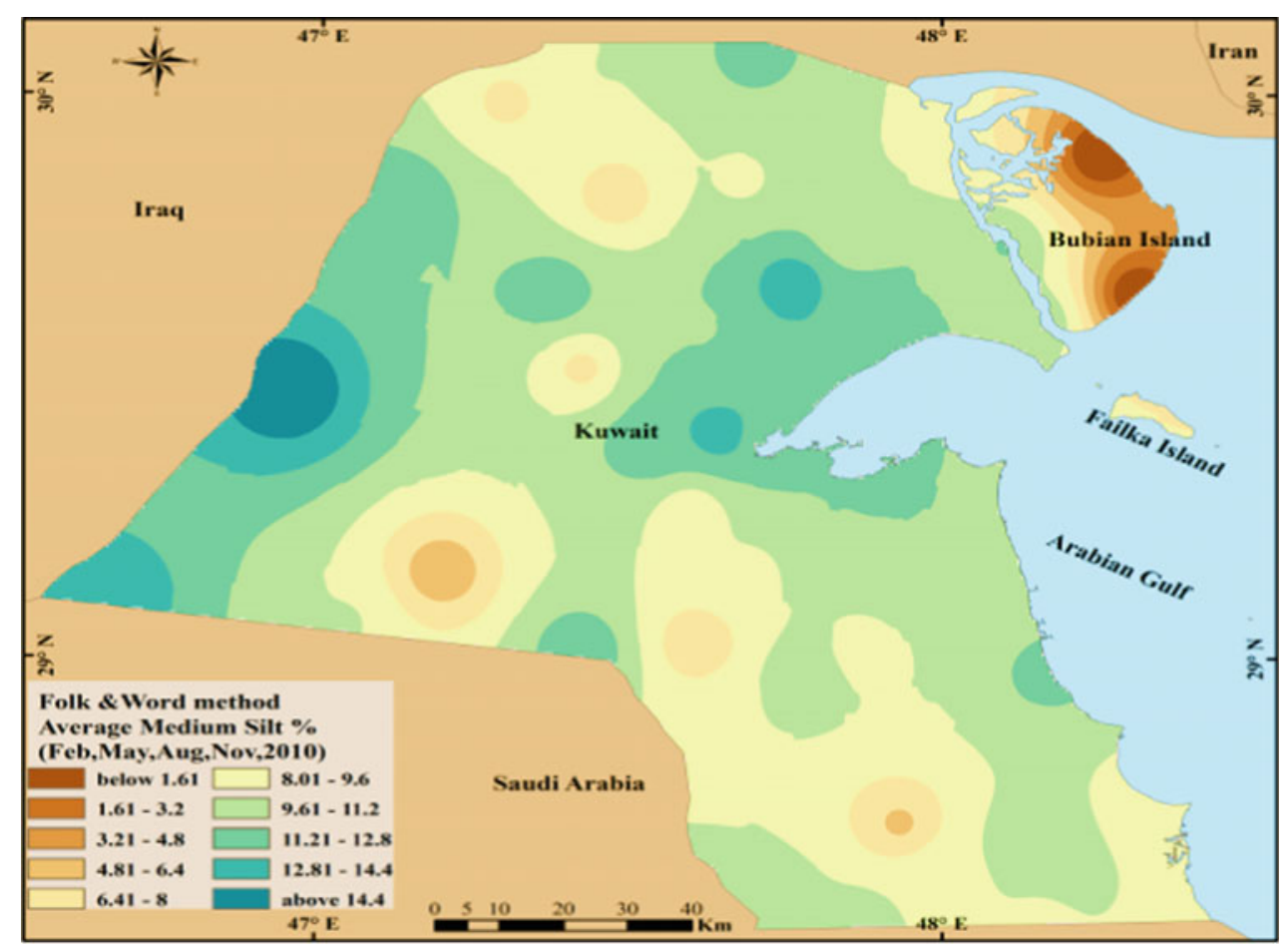

Fig. 3.13 Average percentages of medium silt in the deposited dust (February, May, August, November 2010)

Medium silt (M. Silt) ranges in size between $0.008 \mathrm{~mm}$ and $0.016 \mathrm{~mm}(6-7 \mathrm{phi})$. M.Silt was present in higher percentages around Kuwait Bay and Wadi Al-Batin at the western borders of Kuwait. The lowest percentages were recorded in February, while the highest were observed in May. Preserved areas (Liyah, around Kuwait Bay, and the fenced border zone) had the highest percentages of M. Silt. The lowest M. Silt percentages were on Bubiyan Island. The second lowest M. Silt percentages were observed in a corridor that extends from Retqah toward Wafra in Kuwait.

\begin{tabular}{l|l}
\hline $\begin{array}{l}\text { Areas with high particle size } \\
\text { concentration }\end{array}$ & $\begin{array}{l}\text { Areas with low particle size } \\
\text { concentration }\end{array}$ \\
\hline Salmi & Bubiyan Island \\
Ubayriq & Dibdibah \\
Gudhi & Um qudayr \\
Mutla & Um Al Madfi \\
\hline
\end{tabular}



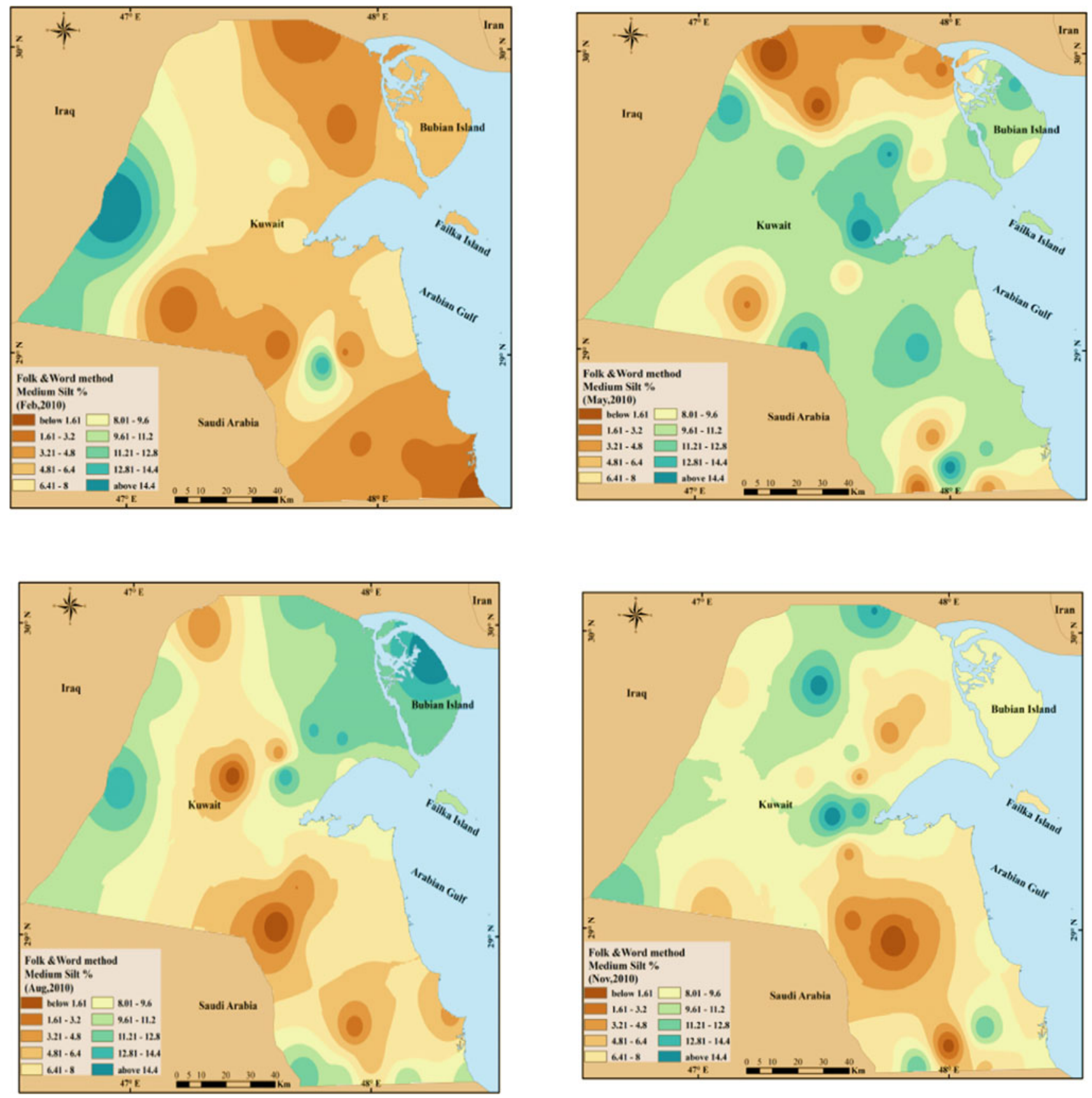

Fig. 3.14 Medium silt size fractions percentages in Feb, May, Aug, Nov 2010 


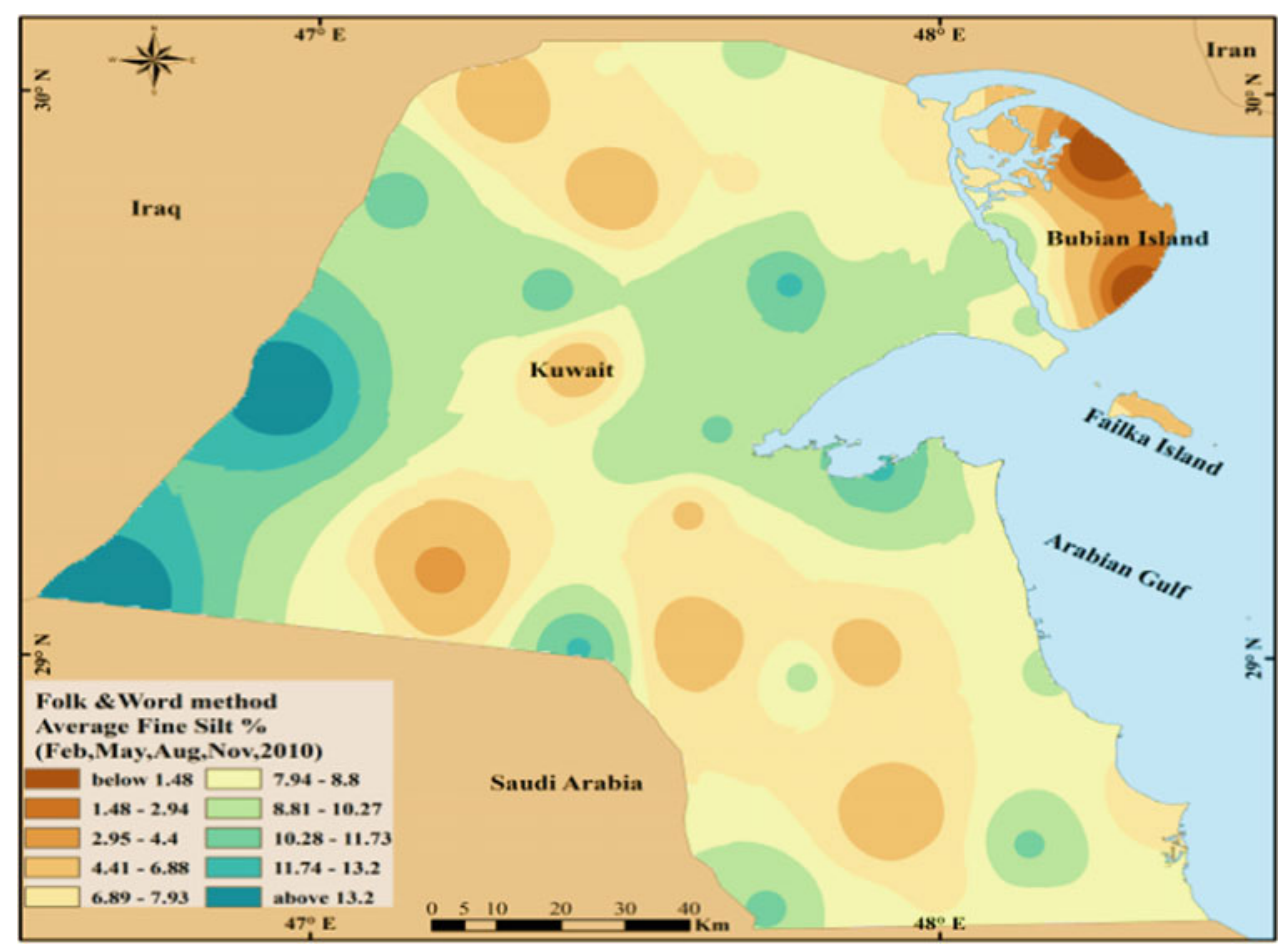

Fig. 3.15 Average percentages of fine silt in the deposited dust (February, May, August, November 2010)

Fine silt (F. Silt) ranges in size between $0.004 \mathrm{~mm}$ and 0. $008 \mathrm{~mm}$ (7-8 phi). Similar to M. Silt, F. Silt was present in higher percentages around Kuwait Bay and Wadi Al-Batin at the western borders of Kuwait. The lowest percentages were recorded during February. During active aeolian processes in August, the lowest percentage rates were noted in a corridor that extends from Retqah toward Wafra in Kuwait. Bubiyan Island had low M. Silt percentages during winter, in February and November, but high percentage rates during summertime in May and August.

\begin{tabular}{l|l}
\hline $\begin{array}{l}\text { Areas with high particle size } \\
\text { concentration }\end{array}$ & $\begin{array}{l}\text { Areas with low particle size } \\
\text { concentration }\end{array}$ \\
\hline Ubayriq & Bubiyan Island \\
Salmi & Dibdibah \\
Gudhi & Um Al Madfi \\
Um Rimam & Qurani \\
\hline
\end{tabular}



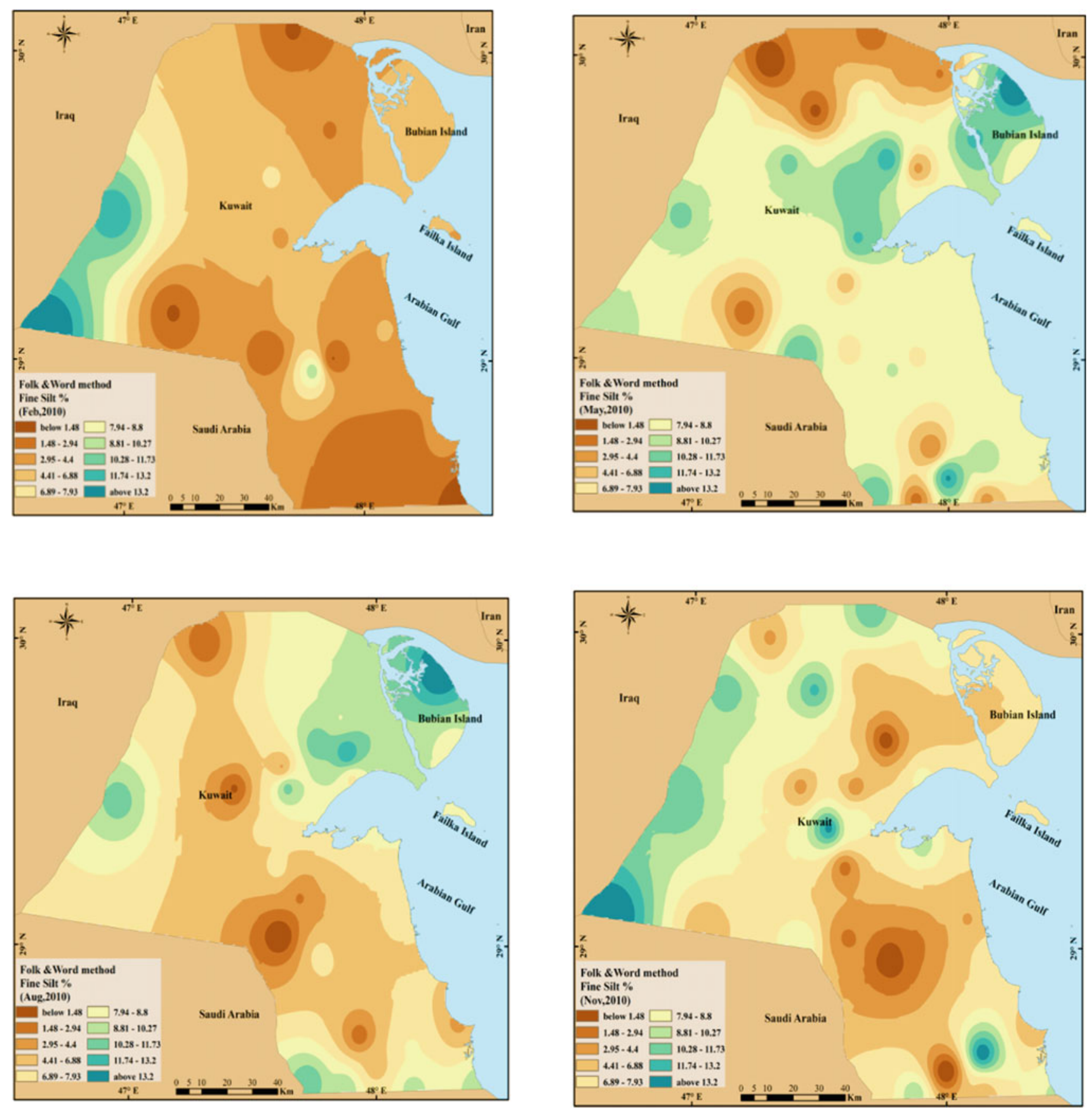

Fig. 3.16 Fine Silt size fractions percentages in Feb, May, Aug, Nov 2010 


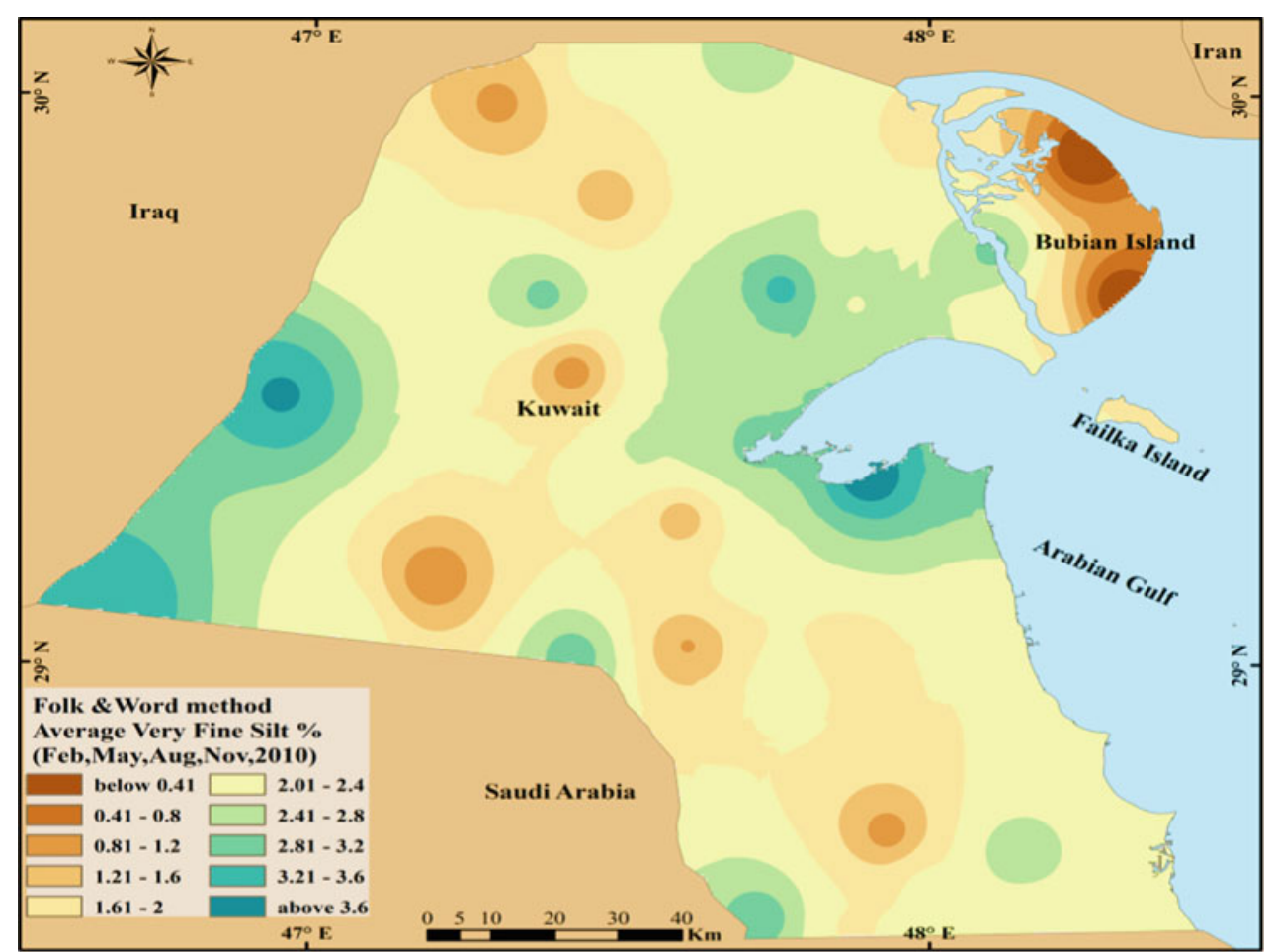

Fig. 3.17 Average percentages of very fine silt in the deposited dust (February, May, August, November 2010)

Very fine silt (V.F. Silt) ranges in size between $0.002 \mathrm{~mm}$ and $0.004 \mathrm{~mm}$ (8-9 phi). Similar to all the other silt size fractions, it was present in higher percentages around Kuwait Bay and Wadi Al-Batin at the western borders of Kuwait. The lowest percentages were noted during February and August. The lowest percentages of V.F. Silt were in a corridor that extends from the Retqah toward Wafra during August. Bubiyan Island had low V.F. Silt percentages during wintertime but high percentages during summertime.
Areas with high particle size concentration

Shuwaikh

Salmi

Ubayriq

Khur Fawaris
Areas with low particle size concentration

Bubiyan Island

Jreshan

Dibdibah

Qurain 

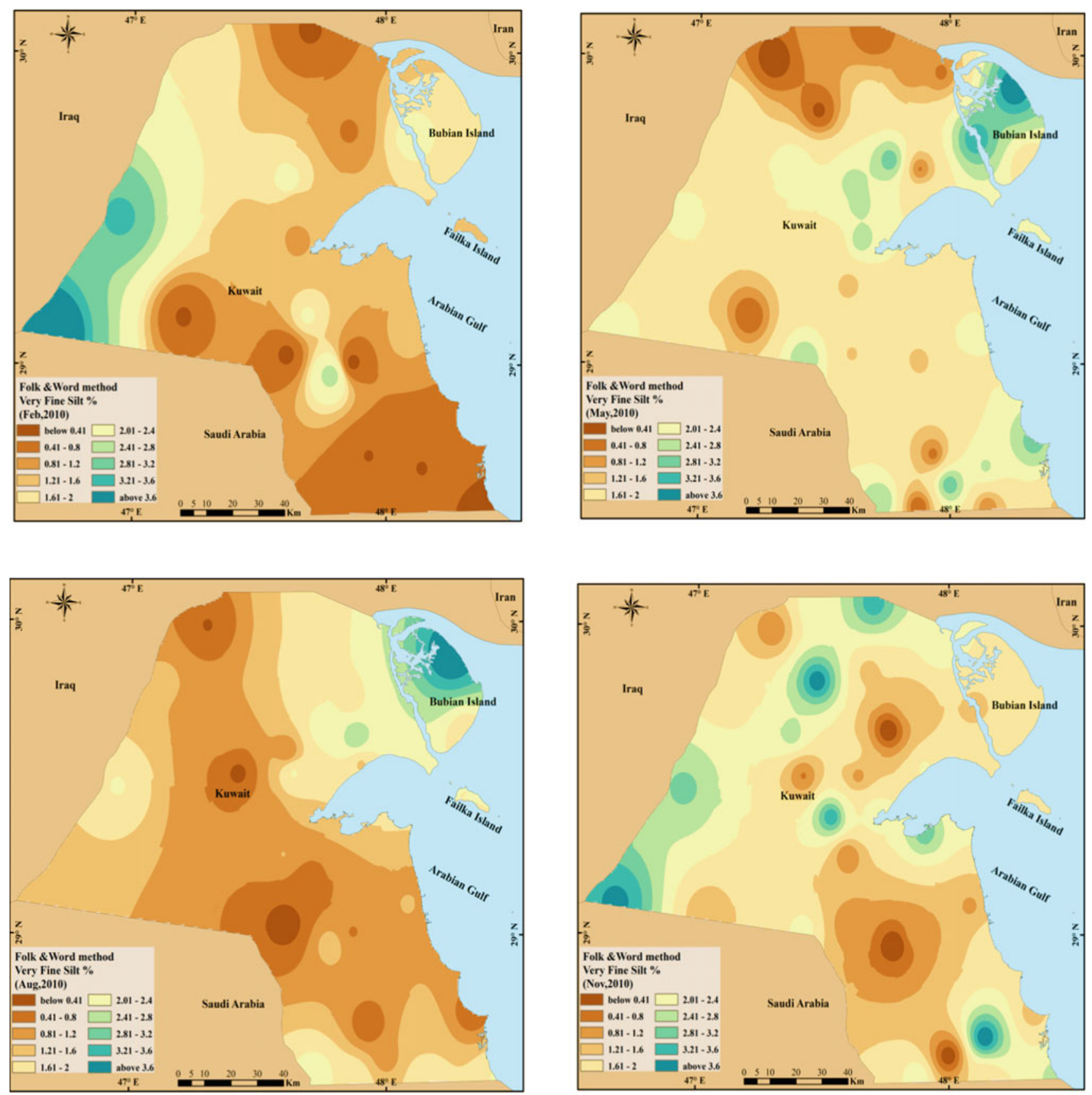

Fig. 3.18 Very fine silt size fractions percentages in Feb, May, Aug, Nov 2010 


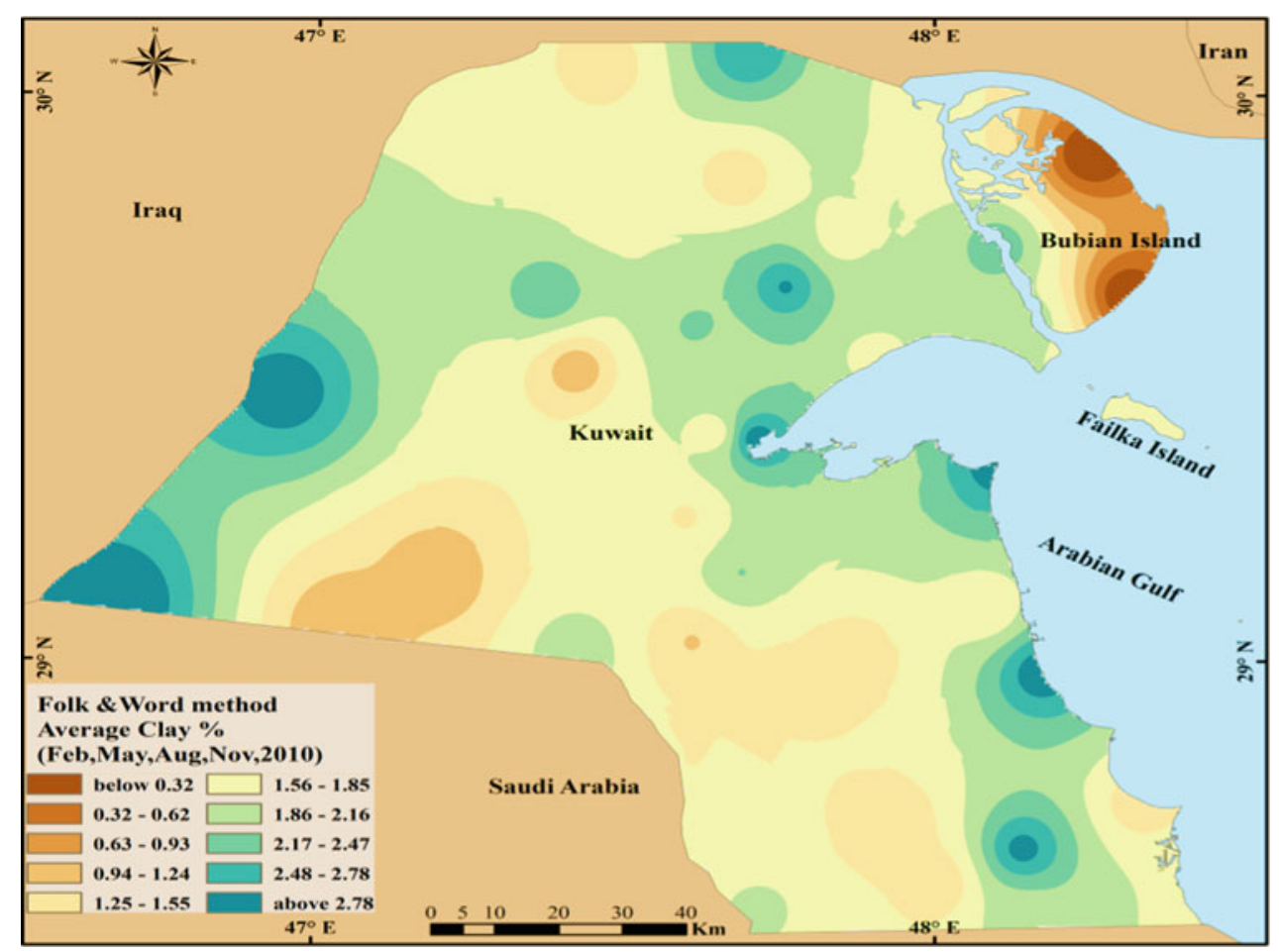

Fig. 3.19 Average percentages of clay in the deposited dust (February, May, August, November 2010)

Clay particle size is less than $0.002 \mathrm{~mm}$ ( 9 phi) and represents a small percentage of fallen dust in Kuwait. Clay presented higher percentage rates around coastal areas, preserved areas, and the Wadi Al-Batin at the western borders of Kuwait. The lowest percentages were during February. Coastal and preserved areas had the highest rates of clay. The western Bubiyan Island contained more clay than the eastern side of the island.

\begin{tabular}{l|l}
\hline $\begin{array}{l}\text { Areas with high particle size } \\
\text { concentration }\end{array}$ & $\begin{array}{l}\text { Areas with low particle size } \\
\text { concentration }\end{array}$ \\
\hline Salmi & Bubiyan Island \\
Ubayriq & Dibdibah \\
Abdulli & Kabd \\
Shuaiba & Qurain \\
\hline
\end{tabular}



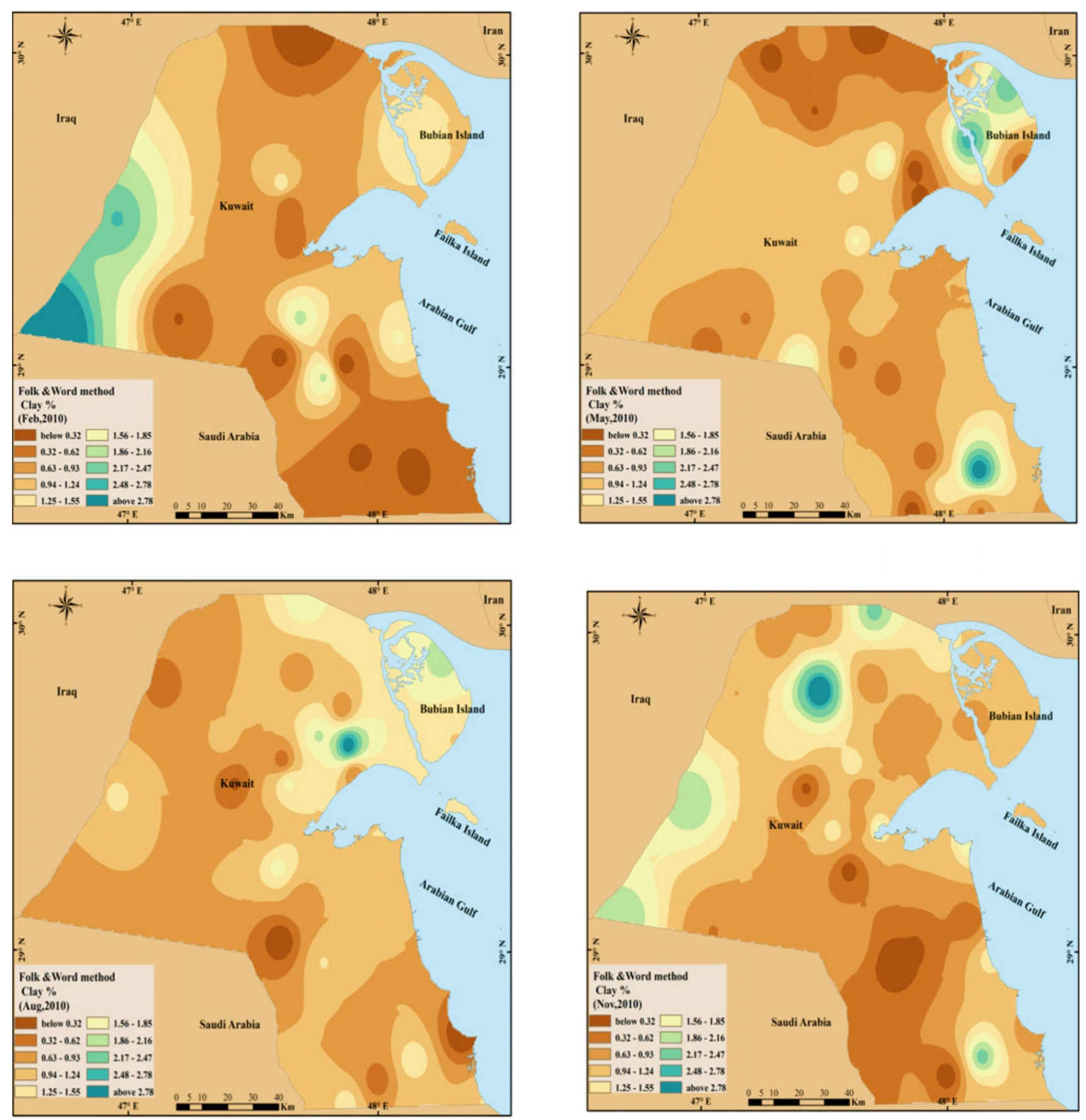

Fig. 3.20 Clay size fraction percentages in Feb, May, Aug, Nov 2010 


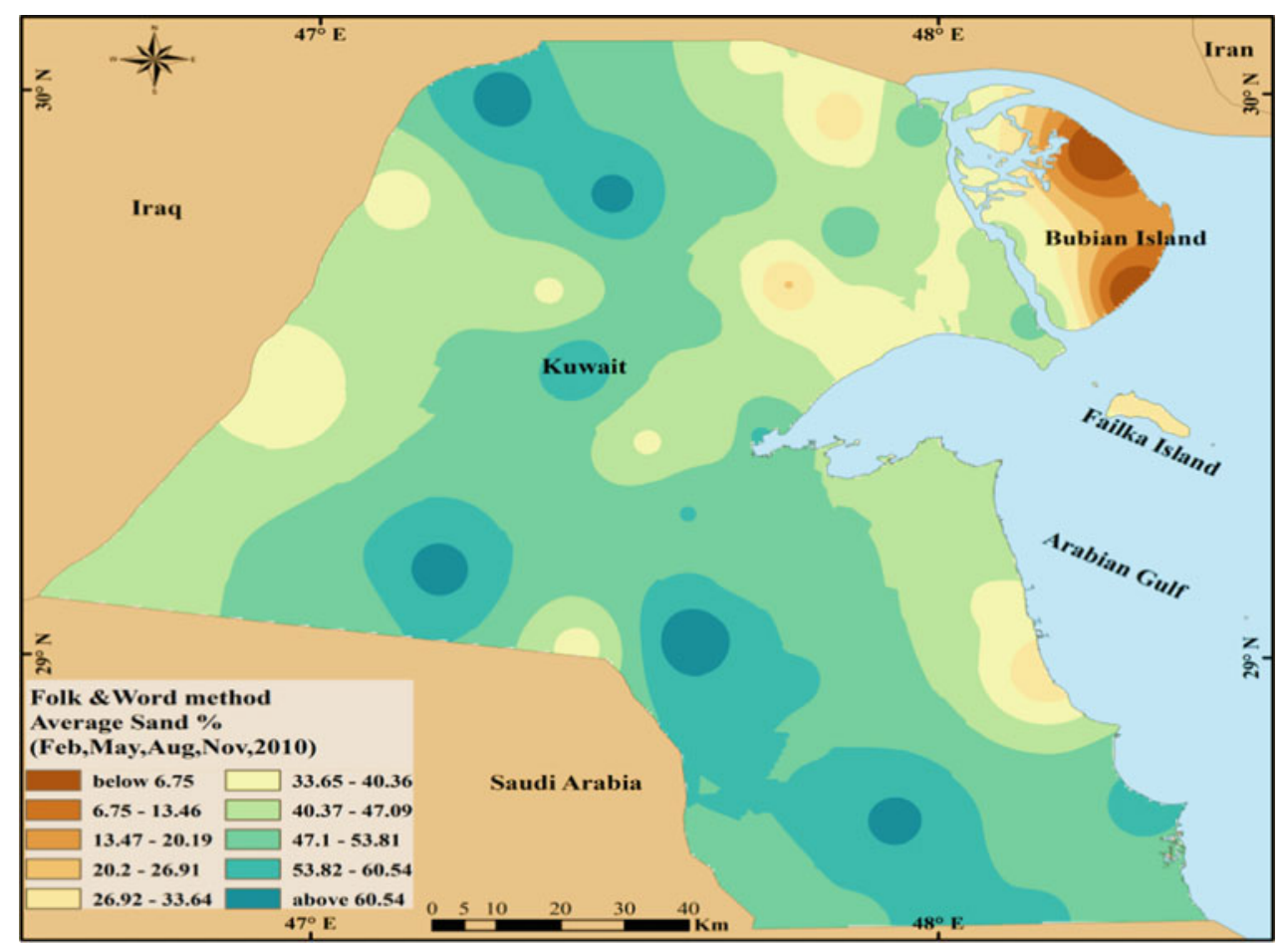

Fig. 3.21 Average percentages of sand in the deposited dust (February, May, August, November 2010)

Sand particles range in size between $2 \mathrm{~mm}$ and $0.063 \mathrm{~mm}$ (4-2 phi). February had the highest percentages of sand. Furthermore, the highest percentages were noted within a corridor that extends from the Retqah toward Wafra, as these areas experienced the highest aeolian accumulation in Kuwait.

\begin{tabular}{l|l}
\hline $\begin{array}{l}\text { Areas with high particle size } \\
\text { concentration }\end{array}$ & $\begin{array}{l}\text { Areas with low particle size } \\
\text { concentration }\end{array}$ \\
\hline Huwaymilyah & Bubiyan Island \\
Dibdibah & Failaka Island \\
Kabd & Shuaiba \\
Qurain & Abdulli \\
\hline
\end{tabular}



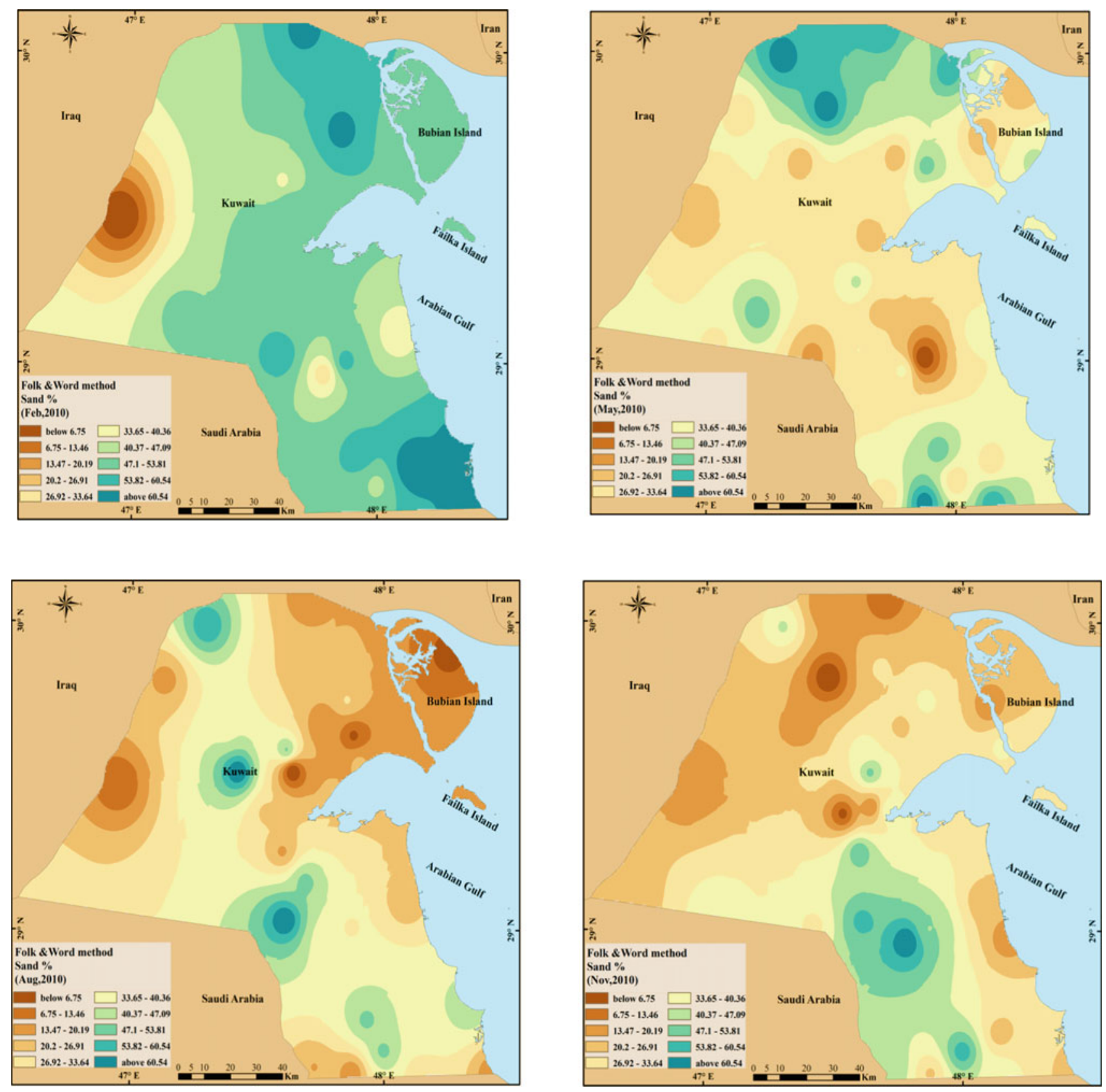

Fig. 3.22 Sand size fractions percentages in Feb, May, Aug, Nov 2010 


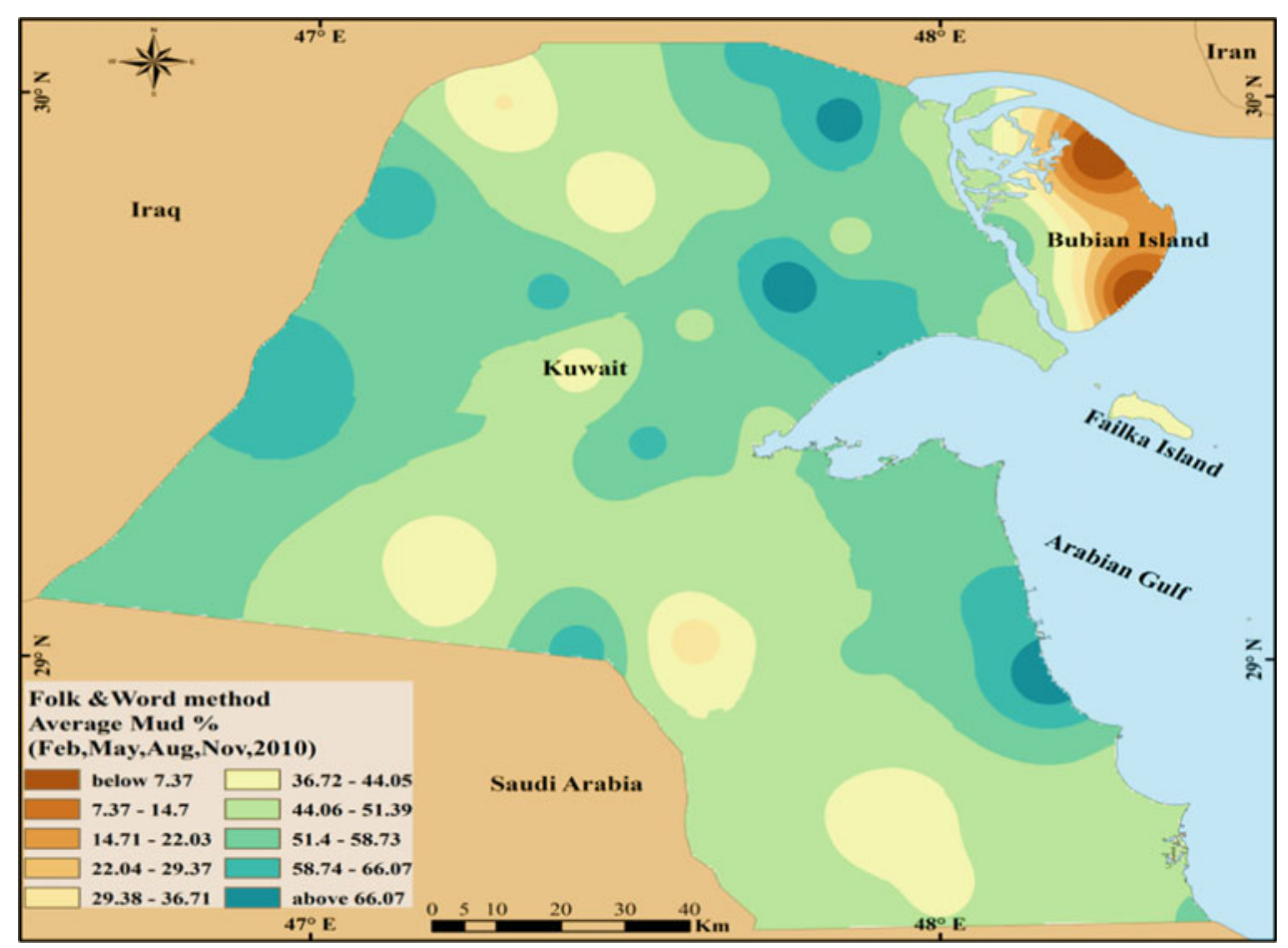

Fig. 3.23 Average percentages of mud in the deposited dust (February, May, August, November 2010)

Mud size fractions are less than $0.063 \mathrm{~mm}$ (4 phi). Mud contains two main size fractions: silt and clay. The northern parts of Kuwait had higher mud percentages than the south. February had the lowest mud percentages, while August and November had the highest percentage rates. The highest percentages were recorded within a corridor that extends from the Retqah toward Wafra, as these areas experienced the highest aeolian accumulation in Kuwait.

\begin{tabular}{l|l}
\hline $\begin{array}{l}\text { Areas with high particle size } \\
\text { concentration }\end{array}$ & $\begin{array}{l}\text { Areas with low particle size } \\
\text { concentration }\end{array}$ \\
\hline Ubayriq & Bubiyan Island \\
Abdulli & Failaka Island \\
Gudhi & Wafra Farms \\
Shuaiba & Ratqah \\
\hline
\end{tabular}



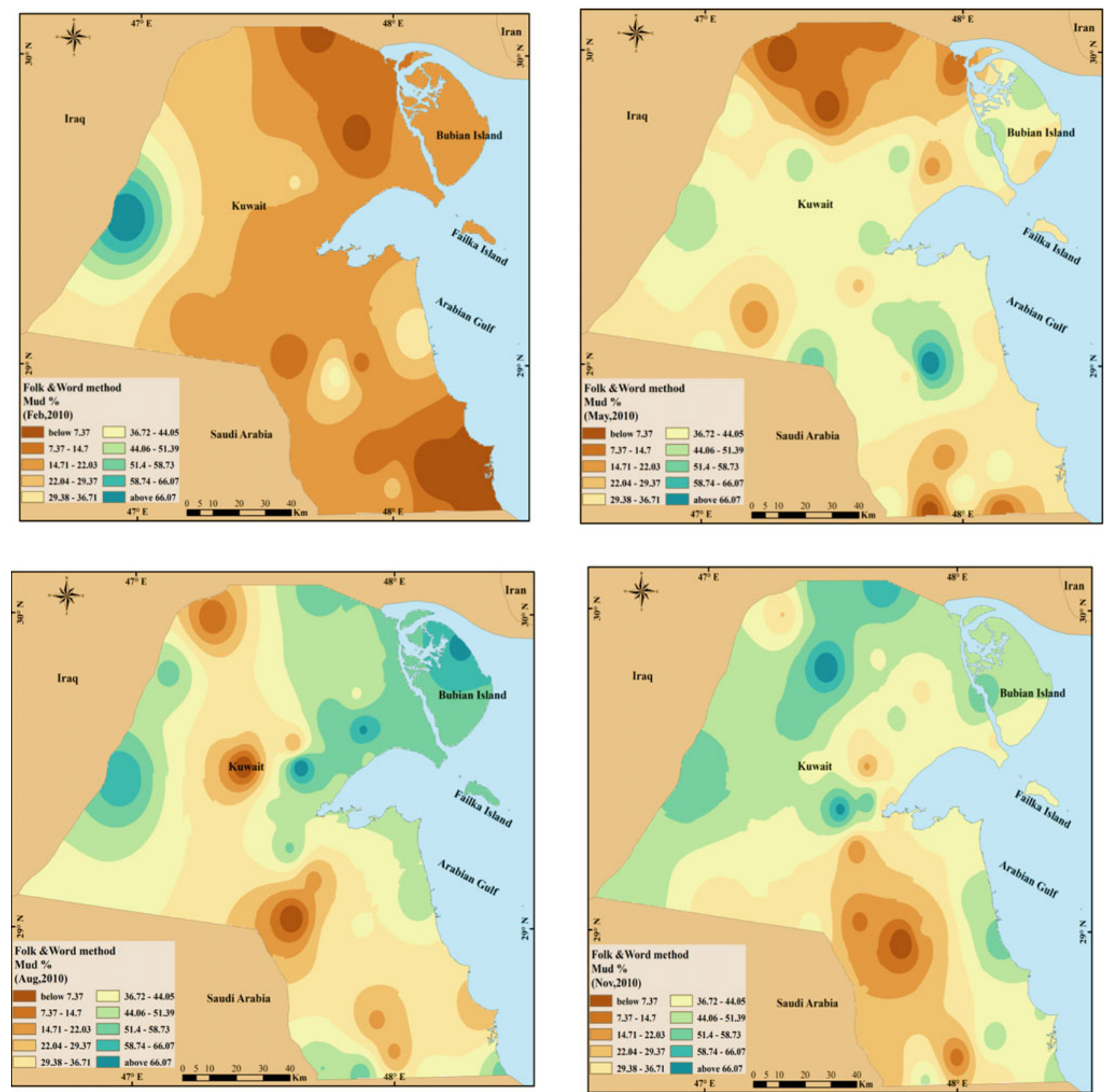

Fig. 3.24 Mud size fractions percentages in Feb, May, Aug, Nov 2010 


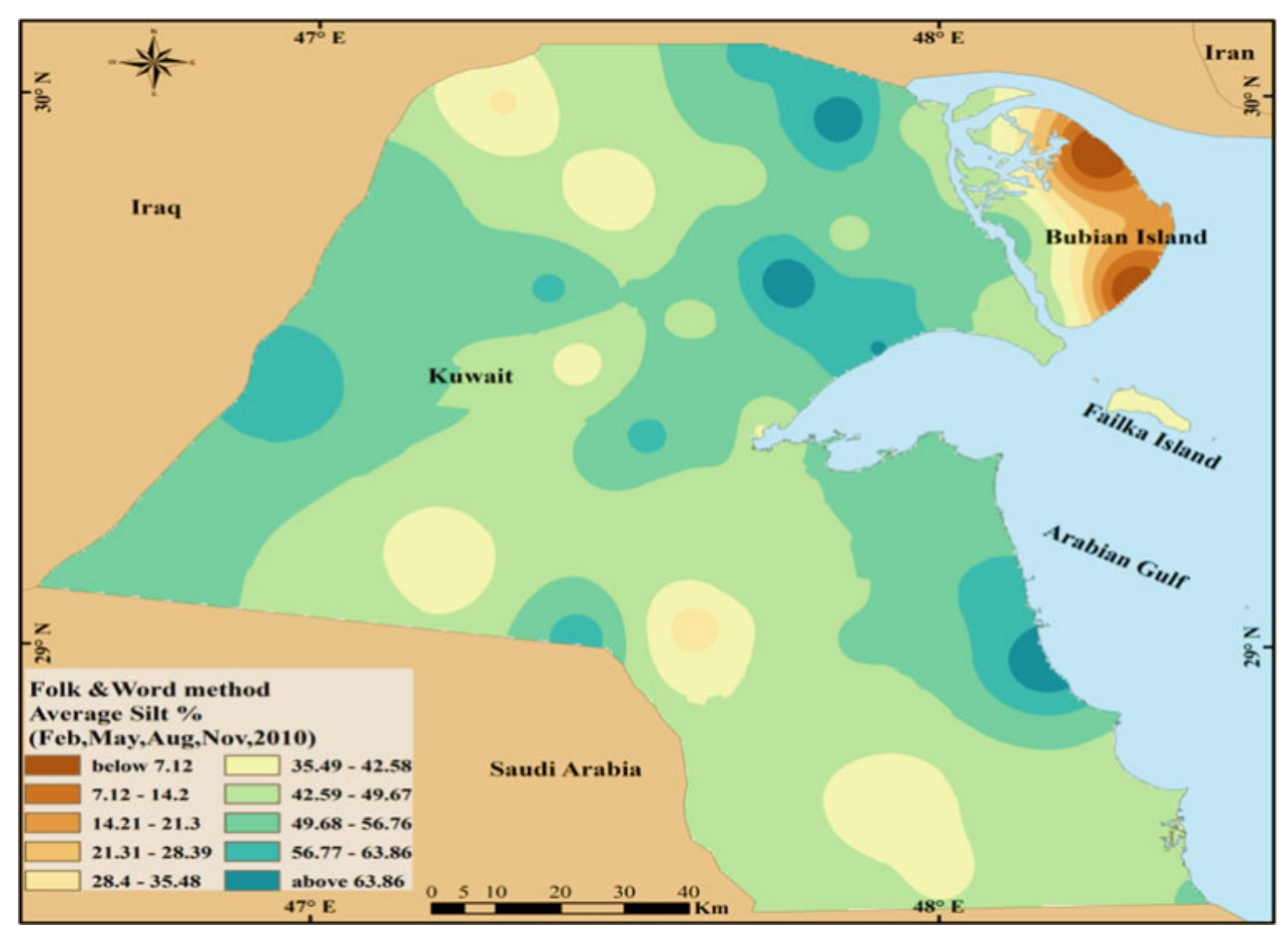

Fig. 3.25 Average percentages of silt in the deposited dust (February, May, August, November 2010)

Silt size fractions range in size from $0.002 \mathrm{~mm}$ to $0.063 \mathrm{~mm}(9-4 \mathrm{phi})$. Similar to mud, northern Kuwait had higher mud percentages than the south. February had the lowest mud percentages, while August and November had the highest rates. Preserved areas were more silt-dominant than other locations in Kuwait.

\begin{tabular}{l|l}
\hline $\begin{array}{l}\text { Areas with high particle size } \\
\text { concentration }\end{array}$ & $\begin{array}{l}\text { Areas with low particle size } \\
\text { concentration }\end{array}$ \\
\hline Ubayriq & Bubiyan Island \\
Abdulli & Failaka Island \\
Gudhi & Wafra Farms \\
Shuaiba & Ratqah \\
\hline
\end{tabular}



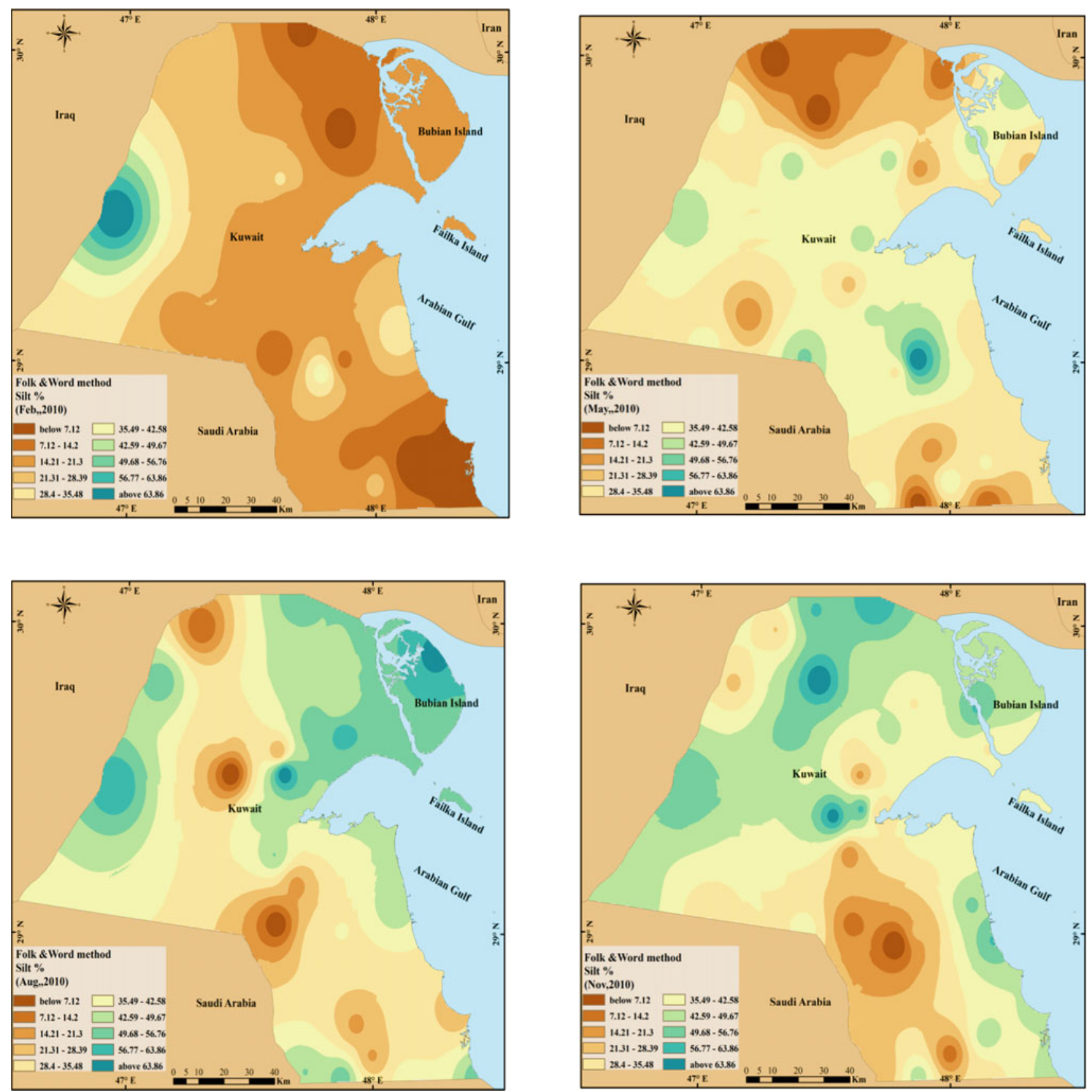

Fig. 3.26 Silt size fractions percentages in Feb, May, Aug, Nov 2010

\section{Methodology}

The parameters proposed by Folk And Ward (1957) have been widely used for quantitative comparisons between natural grain-size distribution and the log-normal distribution that shows better-sorted sediments have lower values of $\sigma 1$ (Table 2). 
Table 2 Terminology applied to graphical statistical parameter values (modified after Folk \& Ward 1957)

\begin{tabular}{l|l|l|l|l|l}
\hline \multicolumn{2}{l}{$\begin{array}{l}\text { Inclusive graphic standard deviation or } \\
\text { (phi sorting) }()\end{array}$} & $\begin{array}{l}\text { Inclusive Graphic Skewness } \\
\text { or (phi skewness) (Sk1) }\end{array}$ & \multicolumn{2}{l}{$\begin{array}{l}\text { Inclusive Graphic kurtosis } \\
\text { or (phi kurtosis) (KG) }\end{array}$} \\
\hline Very well sorted & $<0.35$ & Very positively skewed & $+0.3-+1.0$ & Very platykurtic & $<0.67$ \\
\hline Well sorted & $0.35-0.50$ & Positively skewed & $+0.1-+0.3$ & Platykurtic & $0.67-0.90$ \\
\hline Well sorted moderately & $0.50-0.70$ & Symmetrical & $+0.1--0.1$ & Mesokurtic & $0.90-1.11$ \\
\hline Moderately sorted & $0.70-1.00$ & negatively skewed & -0.1 to -0.3 & Leptokurtic & $1.11-1.50$ \\
\hline Poorly sorted & $1.00-2.00$ & Very negatively skewed & -0.3 to -1.0 & Very leptokurtic & $1.50-3.00$ \\
\hline Very poorly sorted & $2.00-4.00$ & & & & \\
\hline
\end{tabular}
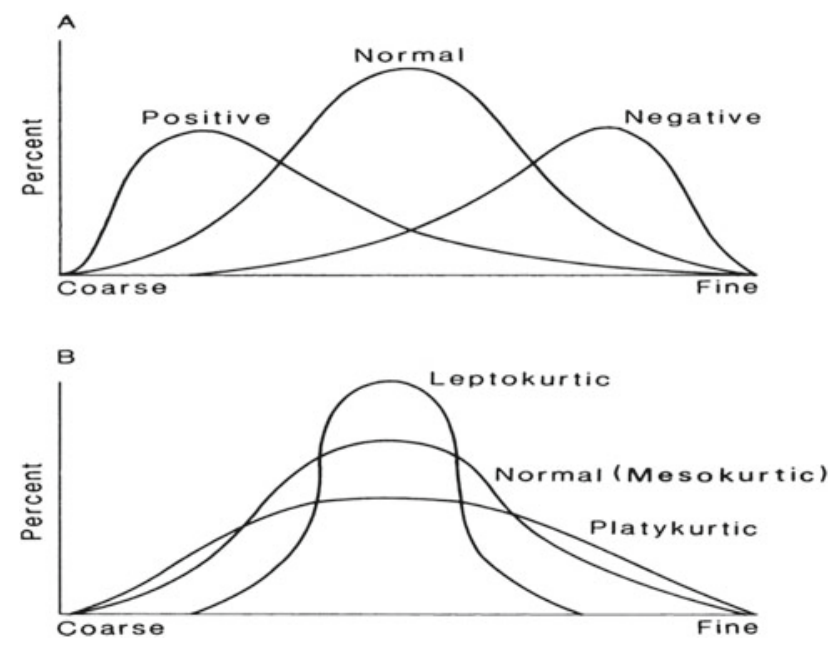

Fig. 3.27 Diagrams illustrating the nature of a skewness (asymmetry) and $\mathbf{b}$ kurtosis (peakedness) in grain-size distributions (Pye and Tsoar, 1990)
Positive values of $\mathrm{Sk} 1$ indicate that the distribution has a more evident trail of fine material compared with a log-normal distribution. In contrast, negative values of Sk1 announce an insufficiency of fine particles compared with the log-normal distribution (Fig. 3.27).

The 'peakedness' or kurtosis of a distribution is indicated by the inclusive graphic kurtosis:

Frequency distributions, which are flatter than a normal probability curve, are referred to as platykurtic, and strongly peaked curves are described as leptokurtic. Intermediate curves are referred to as mesokurtic (Table 2, Fig. 3.27).

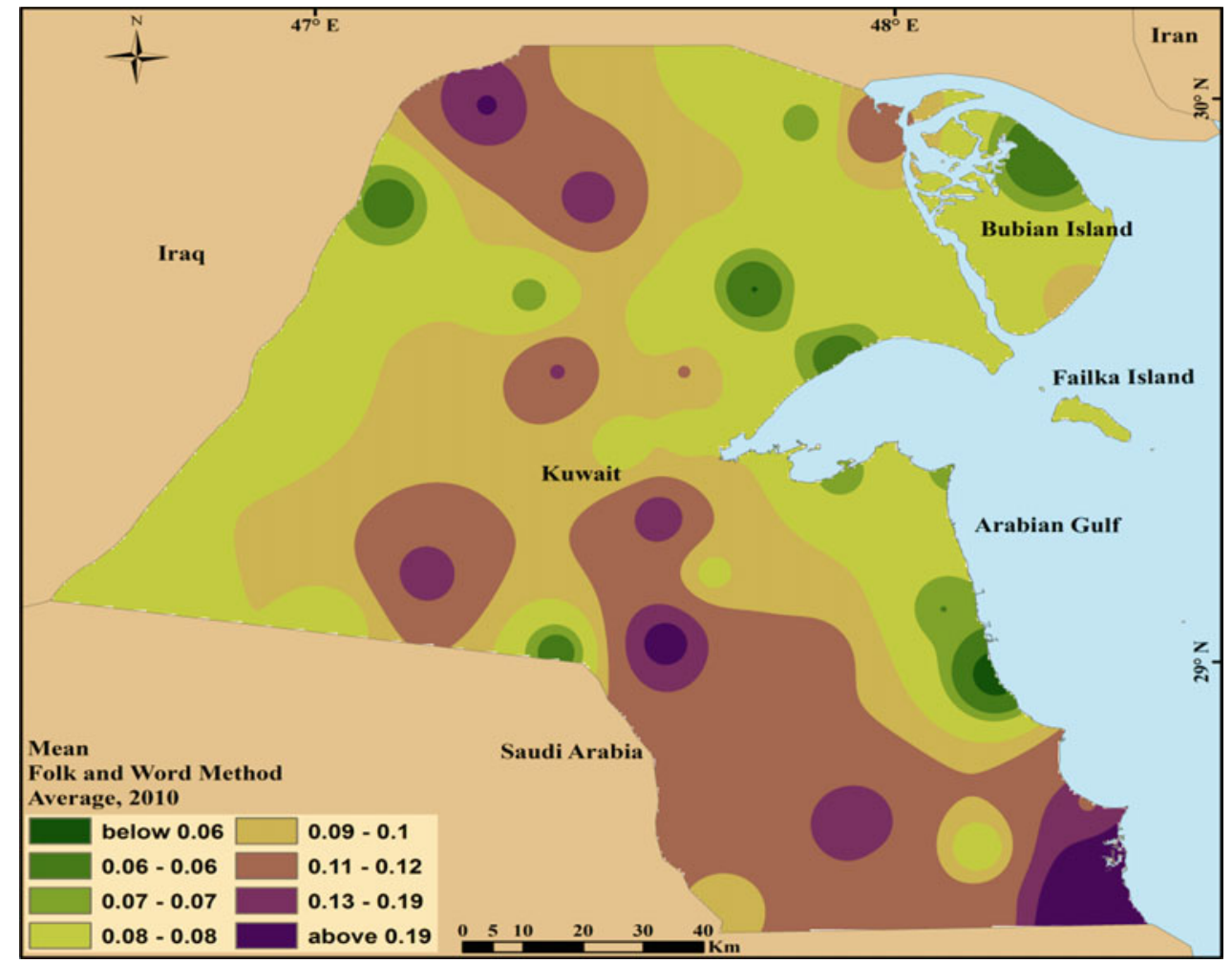

Fig. 3.28 Average statistical parameters (mean) for the deposited dust. (February, May, August, November 2010) 
The mean particle size for dust fallout in Kuwait was coarser in the southern areas of Kuwait. The particle size ranges from very fine sand to very coarse silt. There was a zone of coarsening dust particle size that extends from the Ratqah, in northern Kuwait, to the south at Wafra Farms. During August, the mean size tended to be smaller, while it is finer during May and November.
Areas with high statistical parameter concentration

\begin{tabular}{l|l} 
Khiran & Bubiyan Island \\
Ratqah & Salmi \\
Dibdibah & Shuaiba \\
Kabd & Ubayriq \\
Wafra Farms & Gudhi
\end{tabular}
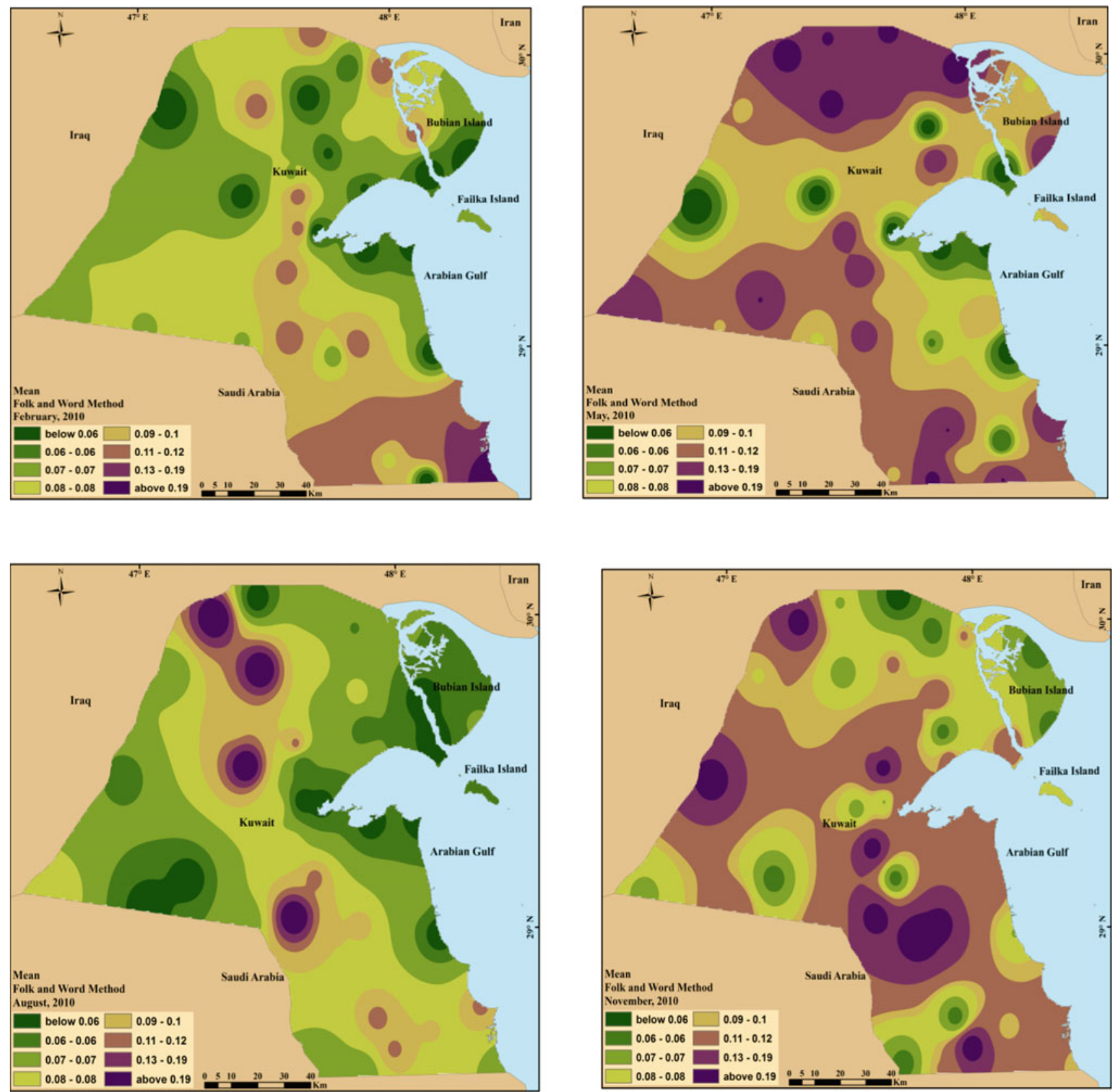

Fig. 3.29 Mean for the deposited dust February, May, August, November 2010 


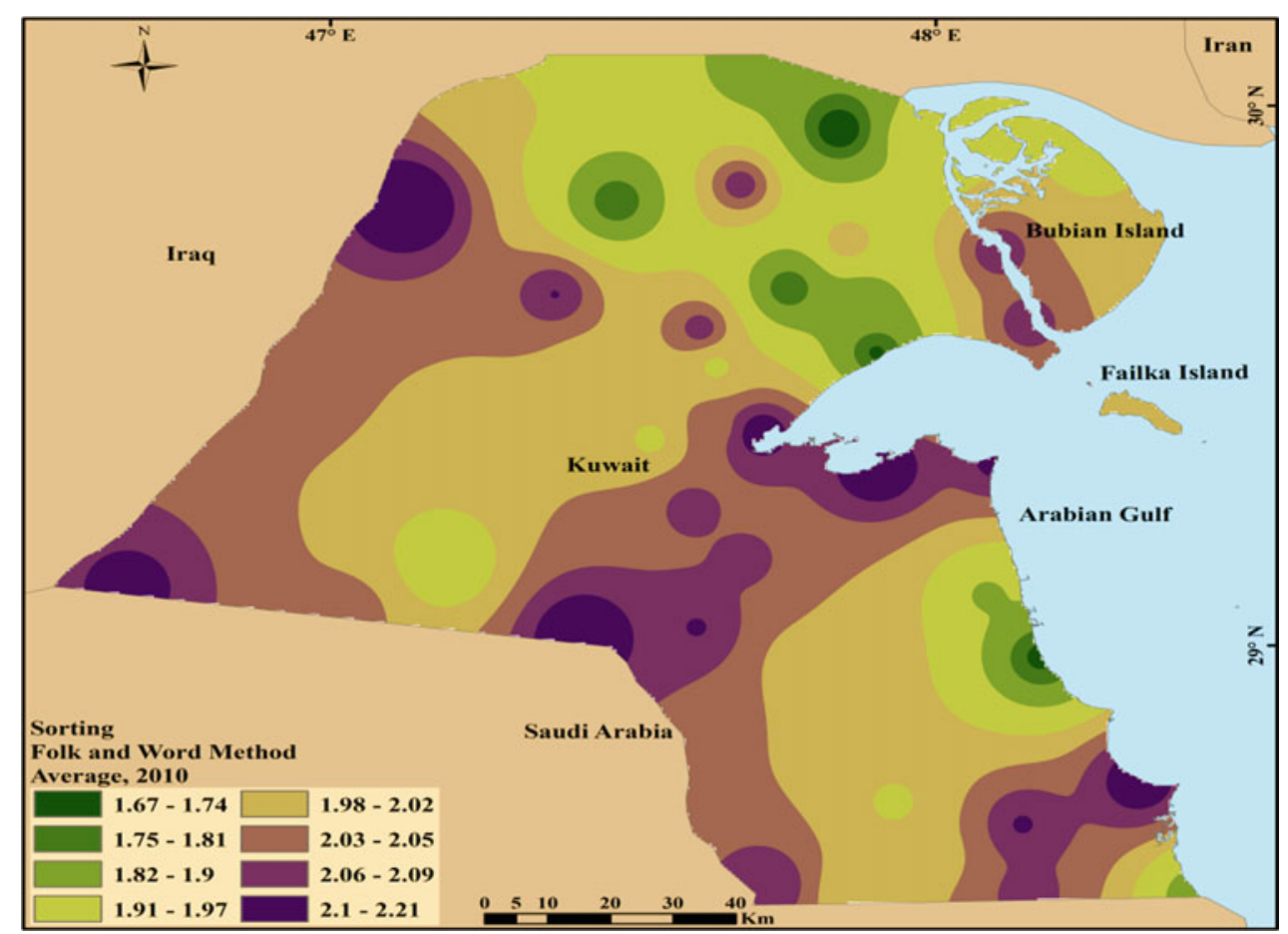

Fig. 3.30 Average statistical parameters (sorting) for the deposited dust. (February, May, August, November 2010)

The dust fallout particles in Kuwait are poorly to very poorly sorted. Particles are very poorly sorted in Wadi Al-Batin, the Jahra, and the southern areas of Kuwait. For all months, the dust fallout particles are better classified around Kuwait Bay.
Areas with high statistical parameter concentration

\begin{tabular}{l|l}
\hline Jreshan & Ratqah \\
Salmi & Dibdibah \\
Kabd & Um Niqa \\
Doha & Shuaiba \\
Khiran & Gudhi
\end{tabular}

Areas with low statistical parameter concentration 

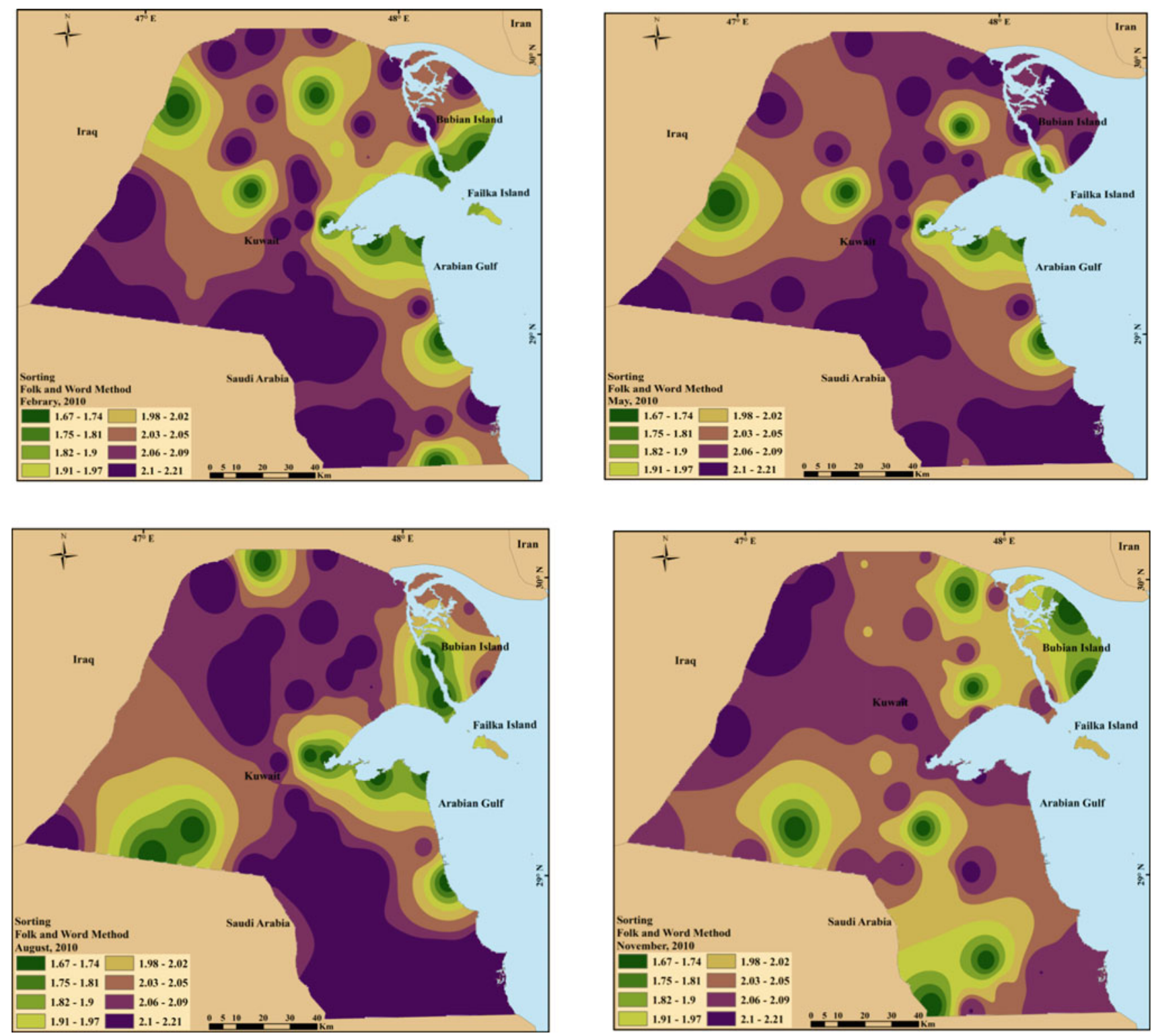

Fig. 3.31 Sorting for the deposited dust February, May, August, November 2010 


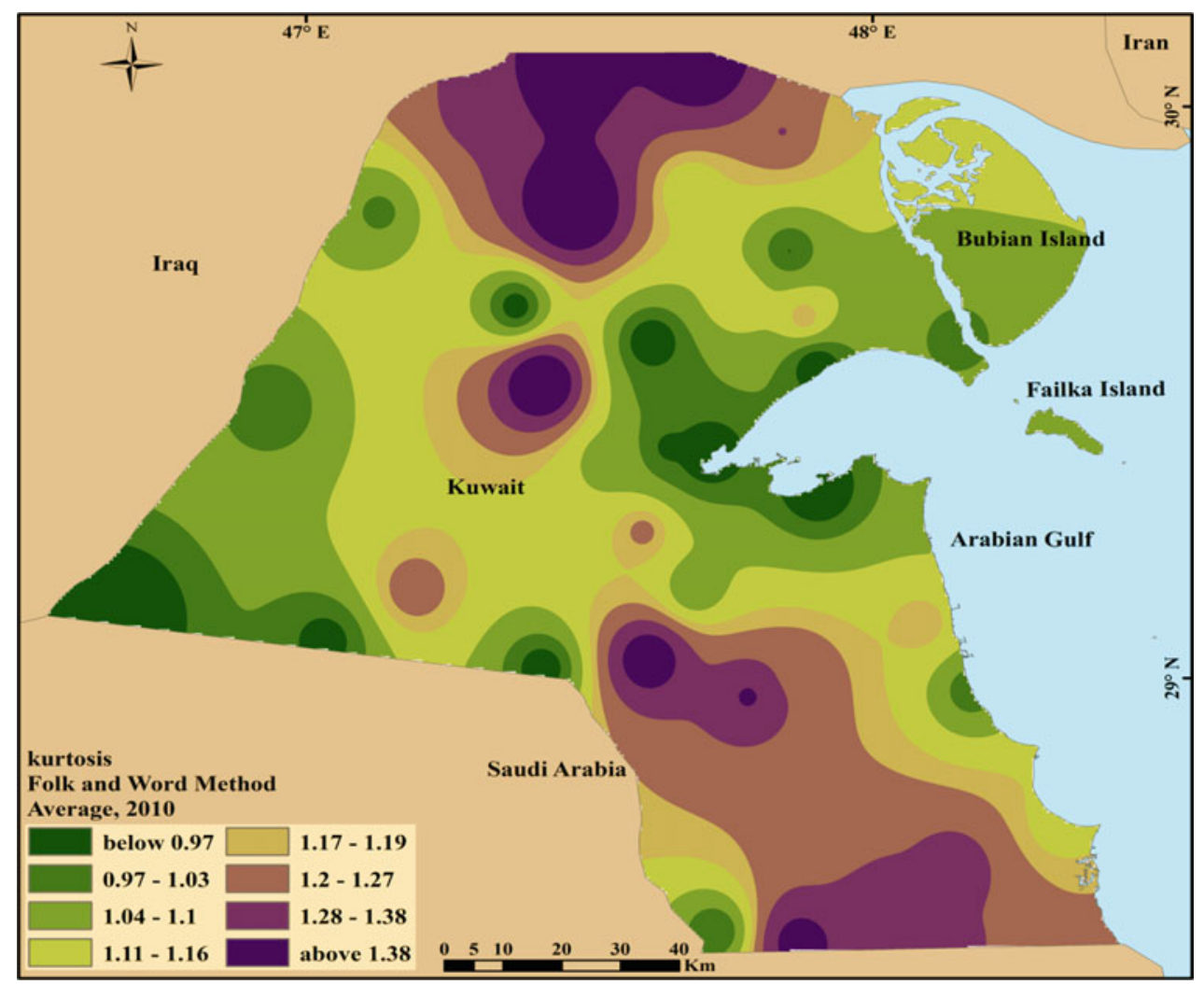

Fig. 3.32 Average statistical parameters (kurtosis) for the deposited dust. (February, May, August, November 2010)

The dust fallout in Kuwait is leptokurtic to mesokurtic. The fallout was leptokurtic in the southern and northern areas of Kuwait, and mesokurtic around coastal areas (mainly around Kuwait Bay) and Wadi Al-Batin at the western borders of Kuwait. Kuwaiti fallen dust tended to be more mesokurtic during February and May. Wadi Al-Batin was characterized by predominantly mesokurtic dust fallout throughout the year.

\begin{tabular}{l|l}
\hline $\begin{array}{l}\text { Areas with high statistical } \\
\text { parameter concentration }\end{array}$ & $\begin{array}{l}\text { Areas with low statistical } \\
\text { parameter concentration }\end{array}$ \\
\hline Abdulli & Bubiyan Island \\
Kabd & Salmi \\
Liyah & Shuaiba \\
Ratqah & Ubayriq \\
Wafra Farms & Mutla \\
\hline
\end{tabular}



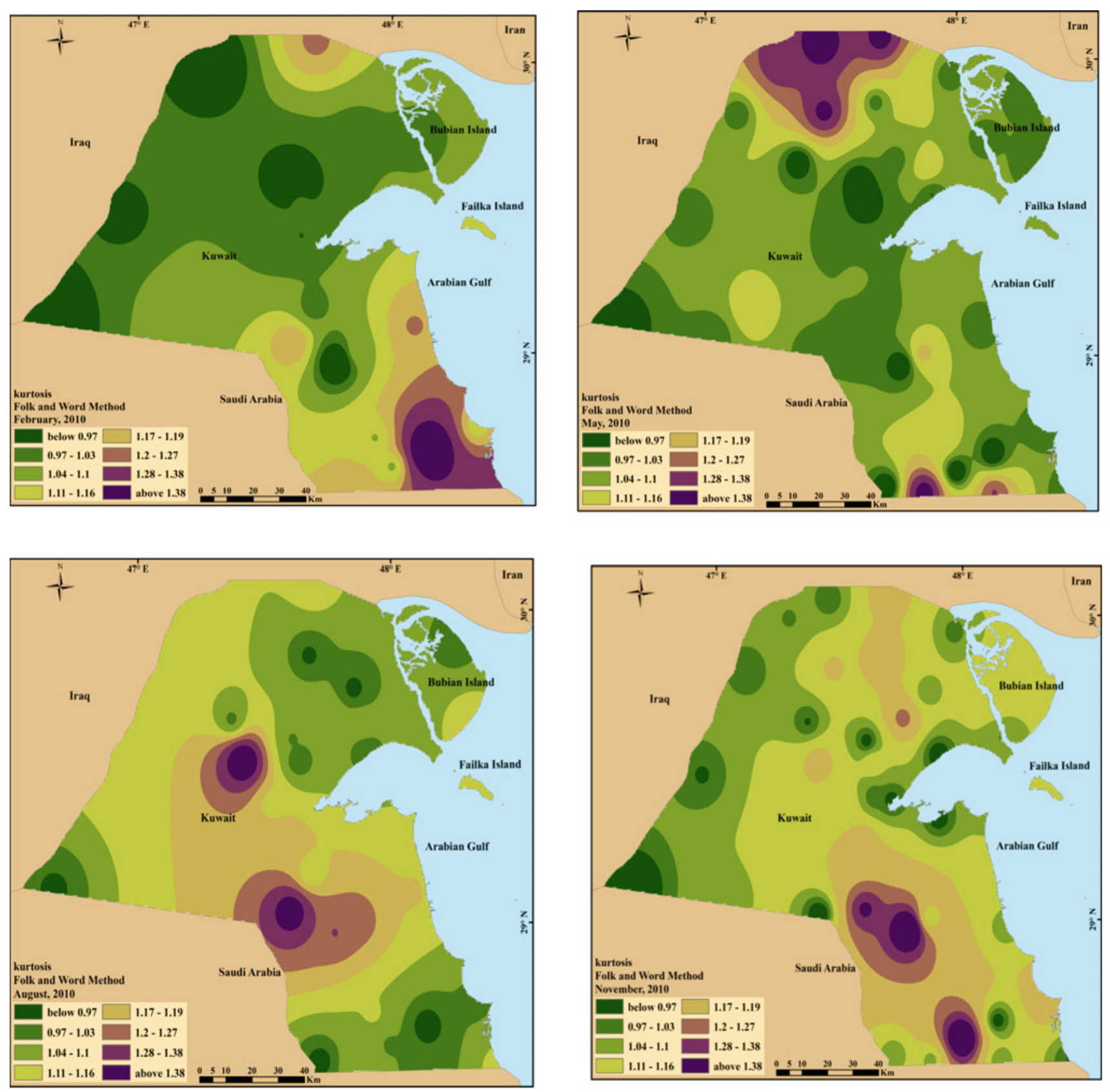

Fig. 3.33 Kurtosis for the deposited dust (February, May, August, November 2010) 


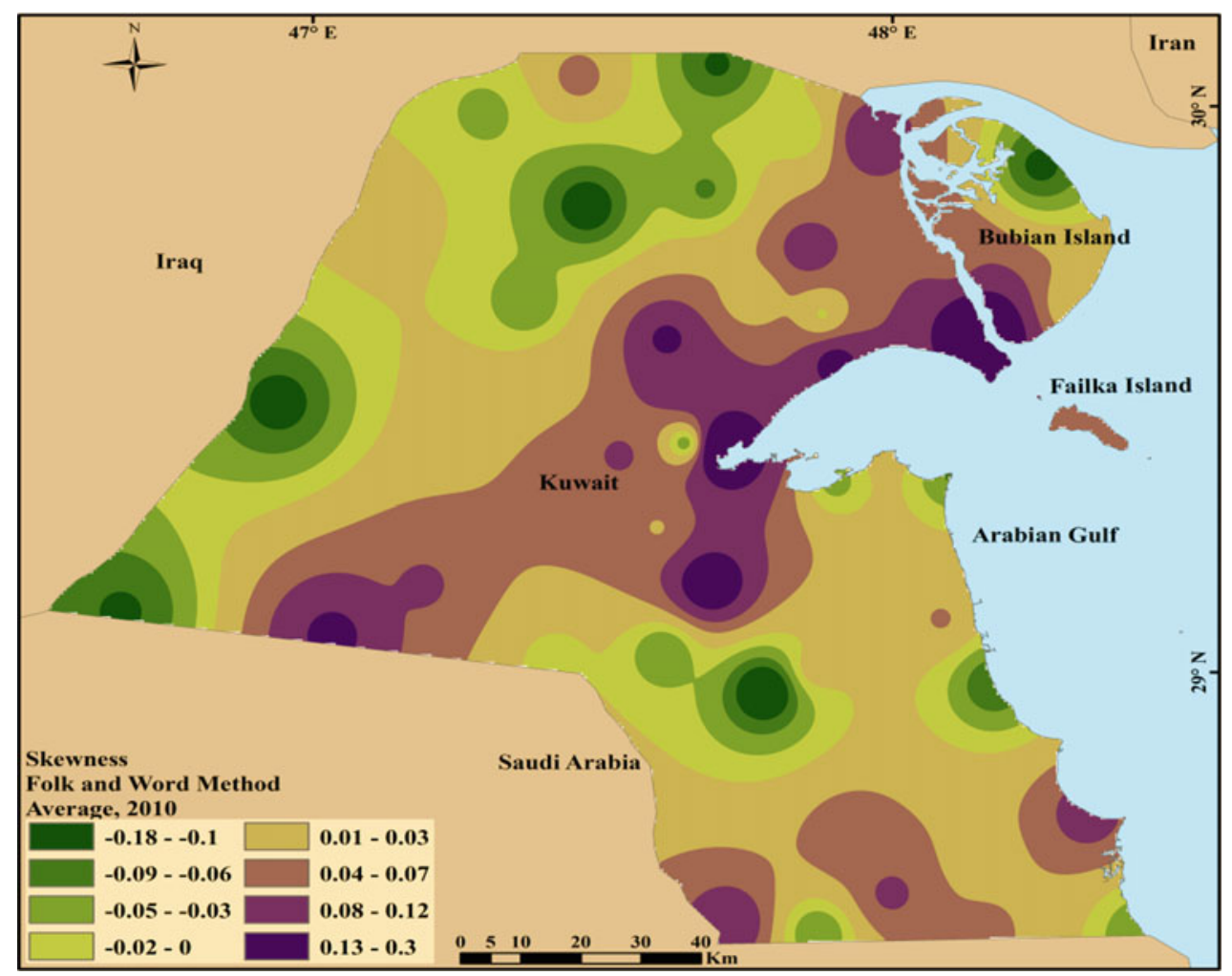

Fig. 3.34 Average statistical parameters (skewness) for the deposited dust. (February, May, August, November 2010)

The dust fallout in Kuwait varies in values from negatively skewed to positively skewed. There were two corridors with positive skewness, the first extends from the Sabiyah toward the Dibdibah, while the second is parallel to the first in the southern areas of Kuwait. Kuwaiti fallen dust tended to be more negatively skewed during August.

\begin{tabular}{l|l}
\hline $\begin{array}{l}\text { Areas with high statistical } \\
\text { parameter concentration }\end{array}$ & $\begin{array}{l}\text { Areas with low statistical } \\
\text { parameter concentration }\end{array}$ \\
\hline Subiyah & Ratqah \\
Dibdibah & Salmi \\
As Sulaibiyah & Shuaiba \\
Doha & Kabd \\
Um Niqa & Um Al Madfi
\end{tabular}



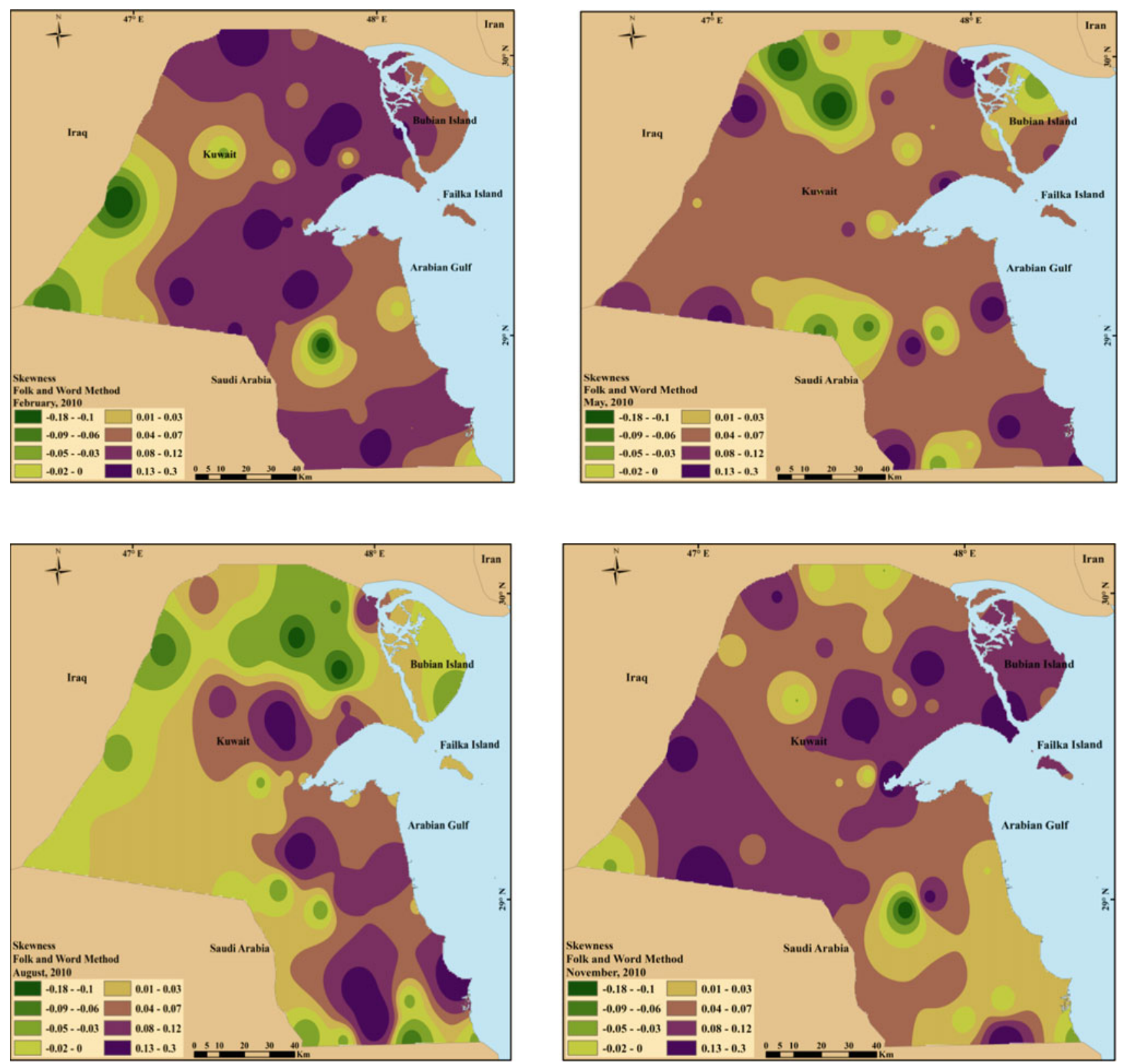

Fig. 3.35 Skewness for the deposited dust (February, May, August, November 2010) 


\section{References}

Carter, R. W. G. (1982). Some problems associated with the analysis and interpretation of mixed carbonate and quartz beach sand, illustrated by examples from north-west Ireland. Sediment Geol, 33, 35-56. https://doi.org/10.1016/0037-0738(82)90026-4.

Folk, R. L., \& Ward, W. C. (1957). Brazos river bar. A study in the significances of grain size parameters. Journal of Sedimentary Petrology, 27, 3-26. https://doi.org/10.1306/74D70646-2B2111D7-8648000102C1865D.

Friedman, G. M., \& Sanders, F. E. (1978). Principles of sedimentology, Wiley and sons, New York. 792.

Kennedy, S. K., Meloy, T. P., \& Gurney, T. E. (1985). Sieve data-size and shape information. Journal of Sedimentary Petrology, 55, 356-360. https://doi.org/10.1306/212F86CA-2B24-11D7-8648000102C1865D.
Komar, Paul D., \& Cui, Bingquan. (1984). The analysis of grain-size measurements by sieving and settling-tube techniques. Journal of Sedimentary Research, 54, 2. https://doi.org/10.1306/212F84812B24-11D7-8648000102C1865D.

Krumbein, W. C. (1934). Size frequency distributions of sediments. Journal of Sedimentary Research, 4, 2. https://doi.org/10.1306/ D4268EB9-2B26-11D7-8648000102C1865D.

Pye, K., \& Tsoar, H. (1990). Aeolian sand and sand dunes. London: Unwin Hyman. p. 458. http://dx.doi.org/10.1007/978-94-011-59869. ISBN 978-94-011-5988-3.

Udden, J. A. (1914). Mechanical composition of some clastic sediments. Bulletin of the Geological Society, 25, 655-744.

Wentworth, C. K. (1922). A scale of grade and class terms for clastic sediments. The Journal of Geology, 30(5), 377-392. https://doi.org/ $10.1086 / 622910$.
Open Access This chapter is licensed under the terms of the Creative Commons Attribution 4.0 International License (http:// creativecommons.org/licenses/by/4.0/), which permits use, sharing, adaptation, distribution and reproduction in any medium or format, as long as you give appropriate credit to the original author(s) and the source, provide a link to the Creative Commons licence and indicate if changes were made.
The images or other third party material in this chapter are included in the chapter's Creative Commons licence, unless indicated otherwise in a credit line to the material. If material is not included in the chapter's Creative Commons licence and your intended use is not permitted by statutory regulation or exceeds the permitted use, you will need to obtain permission directly from the copyright holder. 